\title{
A General Mechanism For Gel Layer Formation On Borosilicate Glass Under Aqueous Corrosion
}

\author{
S. Gin ${ }^{1 *}$, A.H. Mir ${ }^{2}$, A. Jan', J.M. Delaye ${ }^{1}$, E. Chauvet ${ }^{3}$, Y. De Puydt ${ }^{3}$, A. Gourgiotis ${ }^{4}$, S. Kerisit ${ }^{5}$
}

${ }^{1}$ CEA, DEN, DE2D, University of Montpellier, Marcoule, France

${ }^{2}$ School of Computing and Engineering, University of Huddersfield, Queensgate Huddersfield HD1 3DH, $U K$

${ }^{3}$ TESCAN Analytics, ZAC St Charles, 13710 Fuveau, France

${ }^{4}$ Institut de Radioprotection et de Sûreté Nucléaire (IRSN), PSE-ENV/SEDRE/LELI, Fontenay-aux-Roses, France

${ }^{5}$ Pacific Northwest National Laboratory, Physical \& Computational Sciences Directorate, Richland, WA 99352, USA

*Corresponding Author: stephane.gin@cea.fr, tel +33466791465

\section{Abstract}

Mineral and glass dissolution is a scientific topic deeply investigated but incompletely understood and of a great interest for the geochemical and materials science communities. If the interfacial dissolution/reprecipitation mechanism seems to be applicable to most of silicate minerals, the debate remains open concerning glass. Here we studied two model glasses, a ternary borosilicate (CJ1) and the same glass doped with $4.1 \mathrm{~mol} \%$ of $\mathrm{Al}_{2} \mathrm{O}_{3}(\mathrm{CJ} 2)$. The two glasses were altered at $90^{\circ} \mathrm{C}$, $\mathrm{pH}$ 9, and in conditions far and close to saturation with respect to amorphous silica, to determine the initial and residual rates. Moreover, a specific experiment was conducted for a short duration with a solution highly enriched with ${ }^{18} \mathrm{O}$ and ${ }^{29} \mathrm{Si}$ isotopes to understand how passivating gels form. SEM, TEM and ToF-SIMS characterization, along with Monte Carlo simulations were used to understand the rate limiting reactions at play and infer the role of Al. We show that Al yields a slower matrix dissolution in dilute conditions. However, it slows down the formation and the maturation of the passivating gel and favors alteration by partial hydrolysis of Si and Al entities followed by in-situ reorganization/relaxation into a porous network. Unexpectedly, CJ1 experienced both interfacial dissolution/reprecipitation and partial hydrolysis followed by in situ reorganization of the silicate network during the course of a single experiment. This study offers a unified concept that can pave the way for the future development of a predictive kinetic model based on a detailed description of bond breaking and bond forming as a function of glass composition and alteration conditions. 


\section{Introduction}

As glass is a thermodynamically metastable phase, it undergoes irreversible transformation in contact with water. It is a particular concern for applications such as nuclear waste confinement since borosilicate glasses are used to immobilize fission products and minor actinides after spent fuel reprocessing ${ }^{1-4}$. Aqueous corrosion of silicate glass has been intensively studied over the last decades, but, despite significant progress in understanding the mechanisms at play, prediction of glass corrosion behavior still relies on empirical approaches ${ }^{3,5-8}$. Reactions with water generally involve diffusion of water (potentially dissociated) through the unreacted glass (hydration), ionexchange, hydrolysis, and condensation ${ }^{2-3,6,9-10}$. Depending on glass composition and environmental conditions, a silica-rich gel layer can form and potentially limit the mass transfer between the solid and liquid phases ${ }^{11-13}$. In the absence of a gel or when a non-passivating gel is formed, the glass dissolves at the highest dissolution rate (initial dissolution rate $R_{0}$, also called stage I of glass corrosion). When a steady state corresponding to equivalent rates of formation and dissolution of the passivating gel is achieved, the glass dissolves at a residual rate $\left(R_{r} \text {, stage II of glass corrosion }\right)^{14}$. For borosilicate glasses of nuclear interest, $R_{r}$ is typically of 3 to 5 orders of magnitude lower than $R_{0}$ ${ }^{14-15}$. However, although the effects of gels on glass dissolution can be observed directly (slow diffusion of tracers through the gel) or indirectly (dissolution rate measurement), the underpinning mechanisms are insufficiently understood. A wide range of glass corrosion models have been put forward in the literature as a result.

At one end of the spectrum of models, the dissolution-reprecipitation model postulates that glass dissolves congruently in a thin film of interfacial water and that the gel forms by precipitation of sparingly soluble species ${ }^{16-17}$. At the other end of the spectrum, the leaching model proposes that the gel is a relict structure of the glass left behind by preferential leaching of the weakly bonded elements (alkalis, boron) ${ }^{7,9,18}$. Recently, an intermediate model (hydrolysis-in situ condensation model) emerged that describes glass corrosion as partial hydrolysis of Si species (preferential attack of the weakest bonds) followed by in situ condensation ${ }^{19-20}$. Beyond these basic concepts, it is acknowledged that the gel undergoes restructuration ${ }^{19,21-23}$, which implies a time evolution of its physical properties. To evaluate whether each of these models are valid in a restricted domain or if a better understanding of the rate-controlling mechanisms would allow for the emergence of a unified paradigm, we compared the behavior of two simple glasses: a sodium borosilicate glass (CJ1) and a sodium alumino-borosilicate glass (CJ2) with the same Si/B and Si/Na ratios. These two glasses are two simplified versions of the SON68 glass, the inactive surrogate of the French R7T7 nuclear glass produced at La Hague facility. Both initial and residual rates of these glasses were measured at $90^{\circ} \mathrm{C}$ and $\mathrm{pH} 9$, and the early stages of gel formation were investigated using $\mathrm{O}$ and $\mathrm{Si}$ isotopes to quantify 
the exchanges between glass and solution. In addition, Monte Carlo (MC) simulations were performed to better understand the role of Al. This study demonstrates that a model with varying weights of hydrolysis and in-situ condensation reactions depending on glass composition, environmental conditions ( $\mathrm{pH}$, solution composition) and reaction progress can be proposed as a general model for glass corrosion. Additionally, this work highlights the key role played by Al on both glass dissolution and gel properties.

\section{Materials and Methods}

\subsection{Glass preparation}

Details about the synthesis conditions can be found in ${ }^{24}$. $\mathrm{CJ} 1\left(67.7 \mathrm{SiO}_{2}, 18.0 \mathrm{~B}_{2} \mathrm{O}_{3}, 14.2 \mathrm{Na}_{2} \mathrm{O}\right.$ in mol\%) and $\mathrm{CJ} 2\left(64.9 \mathrm{SiO}_{2}, 17.3 \mathrm{~B}_{2} \mathrm{O}_{3}, 13.6 \mathrm{Na}_{2} \mathrm{O}, 4.1 \mathrm{Al}_{2} \mathrm{O}_{3}\right.$ in mol\%) were prepared with analytical grade carbonate or oxide powders and melted twice at $1500^{\circ} \mathrm{C}$ and $1450^{\circ} \mathrm{C}$, respectively. After the second batch, the glasses were annealed for 3 hours at $T_{g}+20 \mathrm{~K}$. Glass powders were prepared following the classical method of grinding, sieving, and ultrasonically cleaning in acetone and ethanol. The following size fractions were recovered: 100-125 $\mu \mathrm{m}$ (for the stage I of glass corrosion experiments), and 40-100 $\mu \mathrm{m}$ (for the long-term stage II of glass corrosion experiments). Specific surface area of the glass powders was calculated assuming spherical particles with a diameter equal to the mean of the particles range. This gives values of $0.022 \mathrm{~m}^{2} . \mathrm{g}^{-1}$, and $0.035 \mathrm{~m}^{2} . \mathrm{g}^{-1}$ for the $100-125$ $\mu \mathrm{m}$ and $40-100 \mu \mathrm{m}$ mesh size, respectively. The absence of fine particles was verified with scanning electron microscope (SEM). For the short-term stage II experiments - experiments devoted to understanding the early stage of gel formation - monoliths were prepared by cutting and polishing at various grades up to a diamond suspension of $0.05 \mu \mathrm{m}$, leading to a surface roughness on the order of a few nm. Before use, monoliths were cleaned in acetone and alcohol.

\subsection{Alteration experiments}

For stage I of glass corrosion, the initial dissolution rates $\left(R_{0}\right)$ of $\mathrm{CJ} 1$ and $\mathrm{CJ} 2$ were measured in static mode, at $(90 \pm 1)^{\circ} \mathrm{C}, \mathrm{pH}^{90^{\circ} \mathrm{C}}$ of $9.0 \pm 0.1$ (adjusted with $\left.\mathrm{LiOH}\right)$, low glass-surface-area-to-volume $\left(S_{\text {geo }} / \mathrm{V}\right)$ ratio of $10 \mathrm{~m}^{-1}$ for 5 and $10 \mathrm{~h}$, respectively. Experiments were conducted in perfluoroalkoxy (PFA) vessels placed in an oven. The solution was continuously stirred with a magnetic bar to maintain the glass particles in suspension in the liquid phase. In this configuration, the Reynolds number - a dimensionless number indicating the flow pattern - was estimated to be $>2000$, a value characteristic of a turbulent flow at the glass surface. 
Short-term stage II rate experiments were conducted as follow. One or two coupons of glass of approximately $5 \times 5 \times 1 \mathrm{~mm}^{3}$ were placed in a $7 \mathrm{~mL}$ PFA vessel filled with approximately 1.5 or $3 \mathrm{~mL}$ of water enriched in ${ }^{18} \mathrm{O}$ and ${ }^{29} \mathrm{Si}$, so that $S_{\text {geo }} / V$ was $45 \mathrm{~m}^{-1}$. Details are given in Table 1 . The initial solutions were saturated with amorphous silica in order to bypass the transient regime between stage I and stage II and favor the formation of a passivating layer ${ }^{25}$. The $\mathrm{pH}^{90^{\circ} \mathrm{C}}$ was adjusted to 9 with $\mathrm{LiOH}$. The experiments lasted 33 days. At the end of the experiments, the coupons were analyzed with time-of-flight secondary-ion-mass-spectrometry (ToF-SIMS). Then, the CJ2 coupon was broken into two pieces. One piece was immersed for 1 day and the other for 10 days at room temperature in an isotopically natural water doped with methylene blue and bromothymol blue, two molecules with a 1-nm hydrodynamic diameter. The behavior of these dyes in the alteration layers will help reveal the existence of channels bigger than $1 \mathrm{~nm}$ and connected to the bulk solution. The solutions of the $33 \mathrm{~d}$ experiments were analyzed by inductively coupled plasma-optical emission spectrometry (ICPOES) and inductively coupled plasma tandem mass spectrometry (ICP-MS/MS).

Long-term stage II experiments were conducted in static mode, at $90^{\circ} \mathrm{C}$ and in deionized water. The test vessel was a $500 \mathrm{~mL}$ PFA reactor filled with $300 \mathrm{~mL}$ of deionized water and $\sim 20 \mathrm{~g}$ of $40-100 \mu \mathrm{m}$ glass powder, corresponding to a $S_{\text {geo }} / V$ ratio of $3000 \mathrm{~m}^{-1}$. To prevent evaporation, each reactor was placed in a bigger container containing a few milliliters of deionized water. The $\mathrm{pH}$ was measured regularly in the bulk solution and samples of $1 \mathrm{~mL}$ each were taken at different time intervals, then acidified and analyzed by ICP-OES. CJ1 was completely altered after 6 years whereas boron is still being released from CJ2 after 21 yr. Approximately $1 \mathrm{~g}$ of corroded glass was sampled after 7800 days (21.4 yr) for SEM and transmission electron microscopy (TEM) characterization. It is worth noting that results from these experiments obtained at shorter times were presented in a previous article ${ }^{24}$.

$R_{0}$ and $R_{r}$ were calculated by least-square linear regression of the normalized mass losses of $i, N L(i)$, where $i$ is a glass dissolution tracer ( $i=\mathrm{Si}$ for $R_{0}$ and $i=\mathrm{B}$ for $R_{r}$ ). NL(i) were calculated allowing for the variations in the fraction of altered glass $(F A G)$, the variation in volume of the leaching solution, and the variations in the reactive surface area of the glass according to a shrinking core model in spherical geometry ${ }^{26}$.

$$
\begin{aligned}
& F A G_{n=1}=\frac{C(i)_{j=1} \cdot V_{0}}{m \cdot x_{i}} \\
& F A G_{n>1}=F A G_{j-1}+\frac{\Delta C(i) \cdot V_{j}}{m \cdot x_{i}} \\
& N L(i)_{n}=\frac{3}{s_{g e o}}\left[1-\left(1-F A G_{n}\right)^{1 / 3}\right]
\end{aligned}
$$


where $n$ refers to the sample number, $S_{g e o}$ is the geometric surface area per gram of starting material, $m$ the mass of glass, $x_{i}$ is the mass fraction of $i$ in the glass, $v_{0}$ the initial volume of the solution and $C(i)_{j}$ the concentration of $i$ in the $j^{\text {th }}$ sample. According to previous studies, the geometric surface area was considered to better represent the actual reactive surface instead of the BET specific area ${ }^{27-28}$. The equivalent thickness of altered glass, $E T(i)$, can be obtained by dividing $N L(i)$ by the glass density (2.451 g.cm $\mathrm{cm}^{-3}$ and $2.405 \mathrm{~g} . \mathrm{cm}^{-3}$ for $\mathrm{CJ} 1$ and $\mathrm{CJ} 2$, respectively). Uncertainty on $R_{0}$ and $R_{r}$ were estimated according to the work conducted on ISG, a six-oxide reference glass ${ }^{27}$. Although the work by Fournier et al. focused on $R_{0}$ only, here we assume that the same error can be considered for $R_{r}$. Therefore, for both $R_{0}$ and $R_{r}$, a value of $\pm 30 \%$ is used in our study, accounting for errors propagation and reproducibility.

\subsection{Solution analysis (ICP-OES, ICP-MS/MS)}

Solutions from the three experiments were analyzed by ICP-OES (Thermo Scientific ICAP 6300 Duo operated at CEA Marcoule) to determine the concentrations of glass cations in solution. For the shortterm stage II experiment, ICP-MS/MS (Agilent 8800 housed at the Institut de Radioprotection et de Sûreté Nucléaire, Fontenay-aux-Roses, France) was used to determine the silicon isotopic ratio, following the method described elsewhere ${ }^{29}$. According to this method, silicon isotope ratio determination was performed in mass-shift mode using $\mathrm{SiO}_{2}{ }^{+}$ion species in order to avoid $\mathrm{Si}$ polyatomic interferences. ICP-MS/MS is a simple and low-cost technique compared to the MC-ICP-MS, providing Si isotope ratios with uncertainties of $\sim 0.5 \%$.

\subsection{Solid Characterization}

\subsubsection{Nuclear magnetic resonance (NMR)}

The ${ }^{11} \mathrm{~B}$ magic angle spinning (MAS) NMR spectra of the borosilicate glasses were collected on a Bruker AVANCE II 500WB spectrometer operating at a Larmor frequency of $160.14 \mathrm{MHz}$ (magnetic field $11.72 \mathrm{~T}$ ) using a $4 \mathrm{~mm}$ (outer diameter of the $\mathrm{ZrO}_{2}$ rotor) Bruker (boron-free) CPMAS probe. The powder samples were spun at a frequency of $12.5 \mathrm{kHz}$. A recycle delay of $2 \mathrm{~s}$ and a pulse length of $1 \mu \mathrm{s}$ (tip angle of about $20^{\circ}$ ) were used to ensure quantitativeness of the spectra (i.e. homogeneous excitation of $\mathrm{BO}_{3}$ and $\mathrm{BO}_{4}$ species, independently of their quadrupolar interactions). Data processing occurred via an in-house code (for details see ${ }^{30}$ ), including the correction of the center band from the contribution of $n=0$ spinning sideband coming from the satellite transition. Results are presented 
in Supplementary information S1. It is calculated that CJ1 and CJ2 have $66 \%$ and $48 \%$ of 4 -fold coordinated B, respectively.

\subsubsection{ToF-SIMS}

ToF-SIMS analyses were performed by TESCAN Analytics (France) with an IONTOF GmbH ${ }^{\odot}$ TOF 5 spectrometer. CJ2 was analyzed in depth profiling mode, whereas CJ1 was analyzed in mapping mode because of its thicker alteration layer. In the mapping mode, it is possible to extract line scan but the resolution is much lower than that obtained in depth profiling mode ( $500 \mathrm{~nm}$ vs $<1 \mathrm{~nm})$. For this reason, we also conducted an analysis of the external part of the gel formed on CJ1 using the depth profiling mode. By combining the two modes, an accurate plot was obtained.

Depth profiling was operated in sputtering mode with two primary beams $\left(\mathrm{Bi}_{1}{ }^{+} 25 \mathrm{keV} 1.5 \mathrm{pA}\right.$ and $\mathrm{O}_{2}{ }^{+}$ $2 \mathrm{keV}, 600 \mathrm{nA}$ to record positive ions and $\mathrm{Bi}_{3}{ }^{++} 25 \mathrm{keV} 0.08 \mathrm{pA}$ and $\mathrm{Cs}^{+} 1 \mathrm{keV}, 90 \mathrm{nA}$ to record negative ions). The abraded area and the analyzed area were $200 \times 200 \mu \mathrm{m}^{2}$ and $50 \times 50 \mu \mathrm{m}^{2}$, respectively. After each cycle of abrasion and analysis, the surface charge was neutralized with a low energy electron beam $(<20 \mathrm{eV})$. At the end, the crater depth was measured with a 3D profilometer. For more details about the application of the ToF-SIMS technique to glass alteration, see ${ }^{31}$.

The mapping mode was performed as follows: for the negative ions mapping, a region of interest (ROI) of $500 \times 500 \mu \mathrm{m}^{2}$ was cleaned with a $2 \mathrm{keV}, 150 \mathrm{nA} \mathrm{Cs}{ }^{+}$beam, then the analysis was performed on a $120 \times 120 \mu^{2}$ square $\left(256 \times 256\right.$ pixels) within the $\mathrm{ROI}$, with a $50 \mathrm{keV}, 0.07 \mathrm{pA} \mathrm{Bi}_{3}{ }^{++}$beam. The positive ions mapping was performed after cleaning another ROI with a $1 \mathrm{keV}, 250 \mathrm{nA} \mathrm{O}_{2}{ }^{+}$beam and analyzing a $120 \times 120 \mu \mathrm{m}^{2}$ area with a $50 \mathrm{keV}, 0.39 \mathrm{pA} \mathrm{Bi}_{3}{ }^{++}$beam.

\subsubsection{TEM specimen preparation and analysis}

A small quantity of corroded glass powder was mixed with ethanol and stirred ultrasonically for about 5 minutes before dropping a few drops of this suspension onto a clean Al foil. The particles on the foil were then coated with a chromium layer of about $120 \mathrm{~nm}$ using a Quorum sputter coater to avoid electrostatic charging and ion beam damage during focused ion beam milling (FIB). A protective carbon layer of about $2 \mu \mathrm{m}$ thickness was then deposited in the region of interest (ROI) of a particle before lifting the particle with the Omniprobe needle and welding it to a custom designed Molybdenum grid. The ROI was then thinned to electron transparency using $30 \mathrm{keV} \mathrm{Ga}$ ions with ion beam current in the range of 300 to $50 \mathrm{pA}$. For TEM analysis, the specimens were cooled to $-130{ }^{\circ} \mathrm{C}$ using a Gatan liquid nitrogen cooled holder and a Hitachi 9500 microscope using $300 \mathrm{keV}$ electrons (flux $<5 \times 10^{17} \mathrm{e} . \mathrm{cm}^{-2} \cdot \mathrm{s}^{-1}$ ). In addition, TEM was also performed on corroded powders crushed in 
ethanol using agate mortar and pestle and dispersed on to a holey carbon TEM grid. The TEM images and pore in the gels were analyzed using Fiji software ${ }^{32}$ and its particle analysis tool.

\subsection{Monte Carlo simulations}

MC simulations were performed to simulate the alteration of CJ1 and CJ2 (with glass compositions given in Section 2.1) and decipher the role of Al on glass corrosion. The MC code used in this study was developed by Kerisit et al. and was described in details in previous publications ${ }^{33-35}$. The algorithm is based on that proposed previously by Devreux and co-workers ${ }^{36}$. The glass structure is represented by a three-dimensional (3D) cubic lattice whose vertices are occupied by network formers (here Si, $\mathrm{B}$, and $\mathrm{Al}$ ), distributed randomly according to their proportion in the considered glass composition ${ }^{33}$. Four-fold connectivity is imposed by removing two bonds per lattice site. Oxygen atoms are not explicitly represented on the network, they are assumed to be in the middle of the bond between two network formers. Network modifiers (here $\mathrm{Na}$ ) are considered to be in interstitial positions near $\mathrm{Si}, \mathrm{B}$, or Al. The contacting aqueous phase is represented by a fixed number of water sites corresponding to the desired surface-area-to-volume ratio (S/V).

Dissolution and condensation reactions are then simulated using a set of predefined probabilities. B sites are dissolved immediately once in contact with the main solution and, due to their high solubility, they are not allowed to redeposit. The formulation introduced by Ledieu et al. ${ }^{37}$ was employed to define the dissolution probability of $\mathrm{Si}$ and $\mathrm{Al}$ sites, $w_{d}$, as a function of the total number of nearest neighbors, $n$, and the number of Al nearest neighbors, $m$ :

$w_{d}(\mathrm{Si}, n, m)=\frac{w_{n}}{f^{m}}$

and

$w_{d}(\mathrm{Al}, n, m)=\frac{w_{n}}{f^{m+1}}$

where $w_{1}, w_{2}$, and $w_{3}$ are dissolution probabilities for Si sites with one, two, or three Si nearestneighbor sites, respectively, and $f$ is a strengthening factor that accounts for the relative strength between $\mathrm{Si}-\mathrm{O}-\mathrm{Al}$ and $\mathrm{Si}-\mathrm{O}-\mathrm{Si}$ linkages. Further, $\mathrm{Si}$ and $\mathrm{Al}$ can redeposit at surface sites with a probability, $w_{r}$, proportional to their concentration, $C_{x}$, in the solution:

$w_{r}=w_{\mathrm{c}-x} * c_{x} \quad(x=\mathrm{Si}$ or $\mathrm{Al})$

$w_{c-x}$ is the condensation probability of species $x$. Probabilities $w_{3}, w_{2}, w_{1}$, and $w_{c-S i}$ were set to $10^{-4}$, $10^{-3}, 10^{-2}$, and 10 , respectively, following Devreux et al. ${ }^{38}$. These probabilities yield a $\mathrm{Si}$ saturation concentration for sodium borosilicate glasses in agreement with the experimental concentration measured at $\mathrm{pH}=8.5$ and $T=90^{\circ} \mathrm{C}$ by Ledieu et al. ${ }^{39}$. The strengthening factor, $f$, and probability $w_{\mathrm{c}-\mathrm{Al}}$ 
were both set to 5 , following Kerisit et al. ${ }^{34}$. These values yield an Al saturation concentration commensurate with that measured by Ledieu et al. ${ }^{40}$ at the same $\mathrm{pH}$ and $T$ conditions.

The algorithm for glass corrosion is summarized below. Each computer step consists of five stages:

1. Dissolution evaluation and execution: Each site in contact with water is evaluated for dissolution using the dissolution probabilities defined above. The dissolved species are replaced by water.

2. Glass connectivity evaluation: The glass configuration is evaluated to determine the connectivity of the glass. Clusters of sites isolated from the main glass are dissolved.

3. Condensation: Si and Al can redeposit at the glass surface using the redeposition probabilities.

4. Liquid connectivity evaluation: Condensation might lead to pore closure. The connectivity of water sites is therefore evaluated to determine whether water sites belong to the main solution or to closed pores. Note that, in the current MC algorithm, dissolution and condensation processes are allowed only for sites connected to the main solution.

5. Coordination evaluation: The coordination of each site is re-evaluated for the new configuration of the glass slab.

These stages are repeated until either the glass has dissolved completely, or a predetermined number of steps has been reached. Simulations were conducted with a glass slab consisting of $64 \times 64 \times 2048$ sites and for a $S / V$ ratio of $2000 \mathrm{~m}^{-1}$. The number of dissolved species was converted to concentration (in $\mathrm{mg} \mathrm{L}^{-1}$ ) by multiplying by the appropriate molecular mass and the water concentration ( $55.5 \mathrm{~mol} / \mathrm{L}$ ). Because the current Monte Carlo model does not capture all the features of the gels described in this work, the simulated passivating layer is referred to as the 'blocking layer' to indicate that the corrosion process stops in the MC simulations when water cannot percolate through this layer and reach the pristine glass.

\section{Results}

\subsection{Initial and residual dissolution rates}

Figure 1 shows the initial and long-term alteration behaviors of $\mathrm{CJ} 1$ and $\mathrm{CJ} 2$, resulting from stage I and long-term stage II glass corrosion experiments, respectively. The initial dissolution rates $R_{0}$ were calculated from the time evolution of the normalized mass loss of Si (Figure 1a). $R_{0}$ of CJ1 and CJ2 at $90^{\circ} \mathrm{C}$ and $\mathrm{pH} 9$ are: $R_{0}(\mathrm{CJ} 1)=11.6 \pm 3.5 \mathrm{~g} \cdot \mathrm{m}^{-2} \cdot \mathrm{d}^{-1}$ and $R_{0}(\mathrm{CJ} 2)=2.6 \pm 0.8 \mathrm{~g} \cdot \mathrm{m}^{-2} \cdot \mathrm{d}^{-1}$, respectively. Both glasses dissolved congruentlty in the tested conditions (supplementary Figure S2 for CJ2), suggesting that i) ion-exchange is negligible and ii) the rate-limiting step is the nucleophilic attack of $\mathrm{OH}^{-}$on $\mathrm{Si}-\mathrm{O}-$ $\mathrm{Si}$ or Si-O-Al linkages. The higher durability of CJ2 can be explained by the presence of Al, which 
increases the resistance of the glass network against hydrolysis in basic conditions ${ }^{40-41}$, and takes some $\mathrm{Na}$ to compensate the negative charge of the four-fold coordinated Al units. Based on $\mathrm{B}$ speciation determined by NMR spectroscopy, CJ1 and CJ2 have $66 \%$ and $48 \%$ of 4 -fold coordinated B, respectively. The amount of $\mathrm{Na}$ as modifier is simply obtained by subtracting the amount of both aluminum and 4-fold coordinated B from the total $\mathrm{Na}$ content. This gives a lower amount of $\mathrm{Na}$ as modifier in CJ2 (0.8 mol\% vs $1.6 \mathrm{~mol} \%$ in CJ1), and therefore a higher degree of polymerization of the glass network.

Figure $1 b$ shows the evolution of the normalized mass losses of $B$ as a function of time for the two glasses altered at high S/V ratio for 21.4 years (long-term stage II experiment). The pH quickly raised to 9.1 for $\mathrm{CJ} 1$ and 9.0 for $\mathrm{CJ} 2$ and remained stable over the whole duration of the experiments. Therefore, the difference in behavior of the two glasses cannot be due to a pH effect. During the first 200 days, the two glasses dissolved at the same rate, and beyond this duration the dissolution rate of CJ2 dropped markedly whereas that of CJ1 remained constant until almost complete alteration of the particles, which happened around $\sim 1800$ days. The fact the two glasses behaved similarly at the beginning of the experiments while CJ1 is intrinsically less durable than CJ2 (see the previous discussion on initial dissolution rate) suggests that passivation occurred sooner for CJ1. This was previously demonstrated for $\mathrm{Zr}$-bearing glasses ${ }^{21-22}$. Interestingly, and for reasons discussed below, $\mathrm{CJ} 2$ eventually developed a more passivating layer than CJ1 causing the rate drop observed in Figure $1 b$.

The residual rate, $R_{r}$, for the two glasses was calculated using a linear regression taken in the linear portion of the curves (Figure 2b): between 200 and 1800 days for CJ1, and between 1000 and 7800 days for CJ2:

$R_{r}(\mathrm{CJ} 1)_{200-1800 \mathrm{~d}}=(2.2 \pm 0.7) \cdot 10^{-2} \mathrm{~g} \cdot \mathrm{m}^{-2} \cdot \mathrm{d}^{-1} ; \mathrm{r}^{2}=0.98$

$R_{r}(\mathrm{CJ} 2)_{1000-7800 \mathrm{~d}}=(1.0 \pm 0.3) \cdot 10^{-3} \mathrm{~g} \cdot \mathrm{m}^{-2} \cdot \mathrm{d}^{-1} ; \mathrm{r}^{2}=0.94$

The ratio $R_{0} / R_{r}$ highlights the efficiency of the passivation layer. It is about 530 for CJ1 and 2600 for $\mathrm{CJ} 2$, suggesting that, the addition of Al to Na-borosilicate glass significantly improves the passivation properties of the gel. However, these experiments on their own are not sufficient to understand how aluminum impacts the gel structure. 

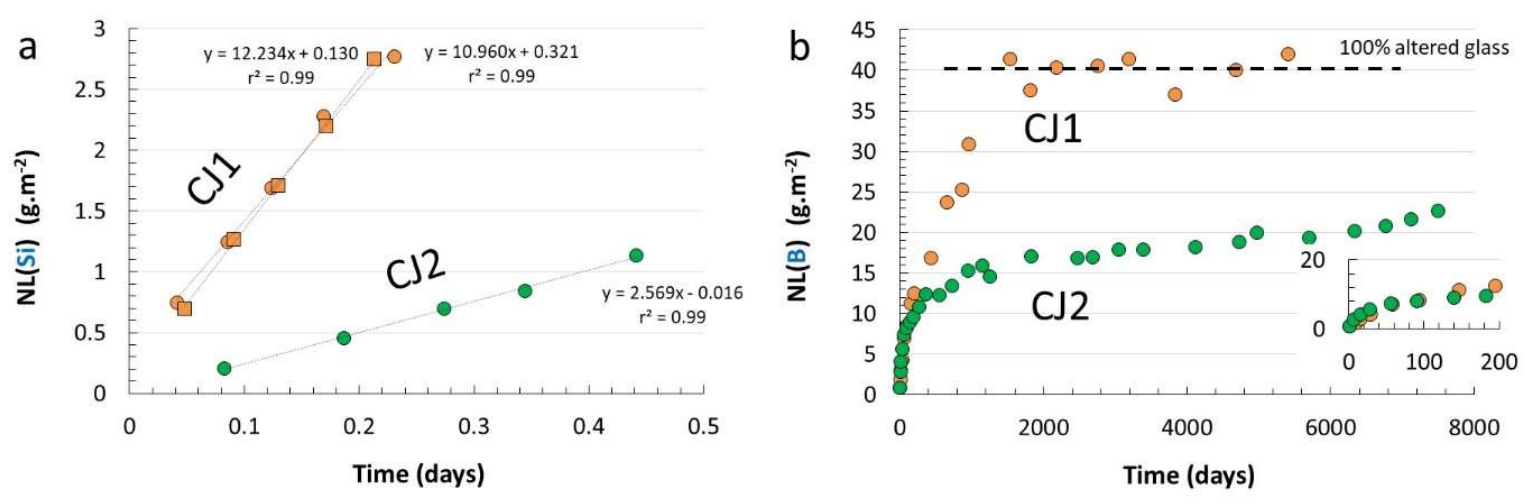

Figure 1. a) Normalized mass loss of $\mathrm{Si}, \mathrm{NL}(\mathrm{Si})$, measured in dilute conditions at $90^{\circ} \mathrm{C}$ and $\mathrm{pH} 9$ (short-term stage I of glass corrosion experiment). For a given experiment, the slope of the curve corresponds to the initial dissolution rate. In this regime, only dissolution takes place. Glasses dissolve congruently meaning that no gel can form. Experiment for CJ1 was duplicated. b) Normalized mass loss of B, $N L(B)$, during the long-term, static experiments (long-term stage II experiment). In this regime, both dissolution and condensation/precipitation take place. $\mathrm{B}$ is used as a tracer because it is not retained in the gel unlike $\mathrm{Si}$ and $\mathrm{Al}$ and $\mathrm{Na}$ acting as charge compensator. CJ1 achieved complete alteration after about 1800 days. The inset in Fig. $1 \mathrm{~b}$ displays the evolution of $\mathrm{NL}$ (B) during the first 200 days.

\subsection{Mechanisms of gel formation}

The mechanisms of gel formation were investigated from the short-term stage II experiment conducted with the two $\mathrm{CJ}$ glasses. The tests were performed at $90^{\circ} \mathrm{C}, \mathrm{pH} 9$ for consistency with the experiments performed to determine the dissolution rates. The solutions were initially saturated with respect to amorphous silica to favor the early formation of a passivation layer ${ }^{25}$. In addition, the solutions were tagged with ${ }^{29} \mathrm{Si}$ and ${ }^{18} \mathrm{O}$ to monitor the exchanges between species present in the solution and in the gel. A post-tracing experiment with dyes was conducted with $\mathrm{CJ} 2$ to better understand the transport of aqueous species within the gel layer. Note that it was not possible to conduct this tracing experiment for CJ1 because the gel was too thick and thus mechanically fragile. Table 1 shows the main solution data before $(t=0)$ and after glass alteration $(t=33 d)$. For $C J 1$, the concentration of $\mathrm{Si}, \mathrm{C}(\mathrm{Si})$ increased by $99 \mathrm{mg} \cdot \mathrm{L}^{-1}$ after $33 \mathrm{~d}$ of experiment. This result indicates that the glass dissolved even though the solution was saturated with respect to amorphous silica, the most soluble silica polymorph. This finding agrees with previous thermodynamical calculations demonstrating that $\mathrm{CJ} 1$ is more soluble than amorphous silica ${ }^{42}$. As a result, the ${ }^{29} \mathrm{Si} /{ }^{28} \mathrm{Si}$ ratio in the solution dropped due to the glass dissolution, a process which supplied the solution mostly with ${ }^{28} \mathrm{Si}$, as glass was made with silica at natural abundance. After 33 days, based on B release, $42 \mu \mathrm{m}$ of CJ1 glass were altered $\left(104 \mathrm{~g} \cdot \mathrm{m}^{-2}\right.$ ) (Supplementary Figure S3), a value higher than that measured in the long-term stage II experiment ( $\sim \mathrm{g} \cdot \mathrm{m}^{-2}$, see inset in Figure $\left.1 \mathrm{~b}\right)$, despite a higher concentration of Si (392 mg. $\mathrm{L}^{-1} \mathrm{vs} \sim 200 \mathrm{mg} \cdot \mathrm{L}^{-1}$ ). The pre-saturation of the solution with respect to amorphous silica is therefore clearly not sufficient to allow an efficient passivation layer to quickly form on CJ1. To do so, the solution needs to be more concentrated to achieve super-saturation, thus allowing precipitation 
to occur. To a first approximation, the time at which the solution achieves super-saturation is inversely proportional to $S / V$. In the short-term stage II experiment with monolith, $S / V$ is 75 times lower than for the long-term stage II experiment conducted with glass powder This can explain the difference in glass reactivity between the two experiments.

Unlike $\mathrm{CJ} 1$, the concentration of $\mathrm{Si}$ in the $\mathrm{CJ} 2$ experiment remained constant. A slight decrease of the ${ }^{29} \mathrm{Si} /{ }^{28} \mathrm{Si}$ ratio was measured. This drop corresponds to an increase of only $0.7 \mathrm{mg} \cdot \mathrm{L}^{-1}$ of ${ }^{28} \mathrm{Si}$, which is equivalent to a thickness of dissolved glass of $2 \mathrm{~nm}$. This thickness is small compared to the thickness of reacted glass $(2.2 \mu \mathrm{m})$. Interestingly, the latter thickness is close to that calculated in the long-term experiment at the same duration $(2.5 \mu \mathrm{m})$. This result strongly suggests that the apparent solubility of $\mathrm{CJ} 2$ is lower than that of amorphous silica and that a passivation gel can form and grow from the beginning of the experiment.

Table 1. Solution data for the short-term stage II glass corrosion experiment conducted in silica-rich and isotopically tagged solutions. Elemental analyses were performed with ICP-OES, Si isotopic ratio were determined with ICP-MS/MS. Normalized mass loss (NL) and Equivalent thickness $(E T)$ were calculated according to formulas given in the Methods section.

\begin{tabular}{|l|c|c|}
\hline & CJ1 & CJ2 \\
\hline Starting conditions & 3.05 & 1.92 \\
\hline Volume $(\mathrm{mL})$ & 45 & 44 \\
\hline $\mathrm{S} / \mathrm{V}\left(\mathrm{m}^{-1}\right)$ & $9.0 \pm 0.1$ & $9.0 \pm 0.1$ \\
\hline $\mathrm{pH}^{90^{\circ} \mathrm{C}}$ & $293 \pm 10$ & $339 \pm 12$ \\
\hline $\mathrm{C}_{\mathrm{i}}(\mathrm{Si})\left(\mathrm{mg} \cdot \mathrm{L}^{-1}\right)$ & $229 \pm 8$ & $147 \pm 5$ \\
\hline${ }^{29} \mathrm{Si} /{ }^{28} \mathrm{Si}$ & $0.52 \pm 0.05$ & $0.45 \pm 0.05$ \\
\hline${ }^{18} \mathrm{O} /{ }^{16} \mathrm{O}$ & & \\
\hline${ }^{\mathrm{Data}}$ at the end of the experiment (Day 33) & $9.0 \pm 0.1$ & $339 \pm 12$ \\
\hline$p H^{90^{\circ} \mathrm{C}}$ & $392 \pm 12$ & $5.5 \pm 0.3$ \\
\hline$C_{f}(\mathrm{Si})\left(\mathrm{mg} \cdot \mathrm{L}^{-1}\right)$ & $104 \pm 5$ & $2.2 \pm 0.1$ \\
\hline$N L(\mathrm{~B})\left(\mathrm{g} \cdot \mathrm{m}^{-2}\right)$ & $42.5 \pm 2$ & $72 \pm 3$ \\
\hline$E T(\mathrm{~B})(\mu \mathrm{m})$ & $0.74 \pm 0.01$ & $\mathrm{n} . \mathrm{d}$. \\
\hline${ }^{29} \mathrm{Si} /{ }^{28} \mathrm{Si}$ & n.d. & \\
\hline${ }^{18} \mathrm{O} /{ }^{16} \mathrm{O}$ & & \\
\hline
\end{tabular}

Results of the ToF-SIMS analyses performed on altered glass samples are displayed in Figure 2 (CJ1) and Figure 3 (CJ2). First, we present results for $\mathrm{O}$ and Si isotopes. By comparing ToF-SIMS analyses of CJ2 before and after the $1 \mathrm{~d}$ and $10 \mathrm{~d}$ tracing experiments, it was verified that the gel was not 
disrupted by the tracing experiment conducted at room temperature (not shown here). The depthprofiling mode was used for $\mathrm{CJ} 2$ and the mapping mode was preferred for CJ1 due to the thickness of the alteration layer. Only the outer layer of CJ1 was analyzed in depth-profiling mode, allowing us to accurately plot the whole profile of ${ }^{29} \mathrm{Si} /{ }^{28} \mathrm{Si}$ (Figure $2 \mathrm{~b}$ ). For both glasses, the alteration layer is highly and homogeneously enriched in ${ }^{18} \mathrm{O}$ with respect to the pristine glass (Figure $2 \mathrm{c}$ and Figure $3 \mathrm{a}$ ). On average, the ${ }^{18} \mathrm{O} /{ }^{16} \mathrm{O}$ ratio in the $\mathrm{CJ} 1$ gel is 0.41 (vs 0.52 in the leaching solution) and 0.27 in the CJ2 gel (vs 0.45 in the leaching solution). The values measured in the gel correspond to $79 \%$ and $60 \%$ of the isotopic ratio of the leaching solution for $\mathrm{CJ} 1$ and $\mathrm{CJ} 2$, respectively, in agreement with the fact that CJ1 hydrolyzes faster than CJ2.

In contrast, the $\mathrm{Si}$ isotopes do not show the same behavior. For $\mathrm{CJ} 1$, the whole alteration layer is enriched in ${ }^{29} \mathrm{Si}$, but the ${ }^{29} \mathrm{Si} /{ }^{28} \mathrm{Si}$ ratio gradually drops from a maximum of $\sim 3$ in the outermost layer to $\sim 0.1$ close to the pristine glass surface (Figure $2 \mathrm{a}$ and $\mathrm{b}$ ). The shape of the ${ }^{29} \mathrm{Si} /{ }^{28} \mathrm{Si}$ profile indicates that the outer gel formed first. Interestingly, the value of 3 measured in outermost layer is greater than the final ratio measured in the solution (0.74) but smaller than that in the starting solution (229). This low value results from the initial dissolution of CJ1 despite the pre-saturation of the solution, which significantly reduced the ${ }^{29} \mathrm{Si} /{ }^{28} \mathrm{Si}$ ratio by releasing a large amount of ${ }^{28} \mathrm{Si}$. This process took place until super-saturation was achieved allowing amorphous silica to precipitate on the glass surface. Assuming that the ${ }^{29} \mathrm{Si} /{ }^{28} \mathrm{Si}$ ratio of 3 in the outermost layer captured the $\mathrm{Si}$ isotopic ratio in solution at the time when precipitation occurred, the glass would have had to supply the solution with $102 \mathrm{mg} \mathrm{L}^{-1}$ of ${ }^{28} \mathrm{Si}$ to lower the silicon isotopic ratio from 229 to 3 . This amount represents a thickness of dissolved glass of $3.0 \mu \mathrm{m}$, a value which is small compared to the $42 \mu \mathrm{m}$ of altered glass measured after 33 days. Under this assumption, the precipitation started when the total concentration of dissolved silica was approximately $400 \mathrm{mg} \mathrm{L}^{-1}$. This concentration is close to that measured at the end of the experiment $\left(392 \mathrm{mg} \mathrm{L}^{-1}\right)$, which supports the initial assumption. One can thus imagine that the concentration of Si raised rapidly to $\sim 400 \mathrm{~m} \mathrm{gL}^{-1}$ and then plateaued due to similar rates of dissolution and precipitation.

This simple mass balance analysis can only account for the formation of the outermost layer with a ${ }^{29} \mathrm{Si} /{ }^{28} \mathrm{Si}$ ratio close to 3 . The fact that the $\mathrm{Si}$ isotopic ratio in the gel decreases with depth (i.e. with time) and reaches values much lower than the final value measured in solution demonstrates that the gel trapped a large fraction of Si from the glass before it entered the bulk solution. This fraction cannot be accurately calculated because the $\mathrm{Si}$ isotopic ratio in solution varied with time and was only measured at the beginning and at the end of the experiment. Nonetheless, a rough estimation can be made according to the final value measured in the solution (0.74). Hence, an isotopic ratio of 
0.2 , such as that recorded in the bulk gel (Figure $2 \mathrm{~b}$ ) can be obtained by mixing $30 \%$ of Si from the solution and $70 \%$ from the glass.

For CJ2, only an outermost layer of 2-4 nm thickness was enriched in ${ }^{29} \mathrm{Si}$ (Figure $3 \mathrm{~b}$ ), whereas the rest of the gel kept the isotopic signature of the glass $(0.06 \pm 0.02$ recorded for both the gel and the pristine glass, a value equal to natural abundance within analytical errors). This enrichment of the surface is consistent with the solution data mentioned above. It is certainly due to a massive reorganization of the original surface of the glass. It is worth mentioning that this observation was made also for ISG altered in similar conditions ${ }^{19-20,43-44}$.

In order to investigate the transport properties of the gel, the altered CJ2 coupon from the 33-d experiment was immersed for 1 and 10 days in a solution containing dyes. This experiment was conducted at room temperature to prevent significant further alteration. ToF-SIMS profiles recorded after tracing show that $\mathrm{S}$ and $\mathrm{Br}$, which are proxies for the dye molecules (methylene blue and bromothymol blue), entered only the outermost layer of the gel (Figure $3 \mathrm{c}$ and d). Beyond $30 \mathrm{~nm}$ for the 1-day tracing test and $10 \mathrm{~nm}$ for the 10-day tracing test, only the background was recorded, with no difference between the gel and the pristine glass. The fact that $\mathrm{S}$ and $\mathrm{Br}$ are seen deeper after 1 day than after 10 days of tracing is unexpected; it might be an experimental artefact due to some roughness in the analyzed area of the 1-day sample. Unfortunately, we performed only one profile for this duration. Nonetheless, the measurements show that the diffusion of the dyes in the gel remains very shallow on the scale of the gel thickness $(2.1 \mu \mathrm{m})$, demonstrating that the bulk gel is a physical barrier that prevents the dye molecules from reaching the gel-glass interface. 

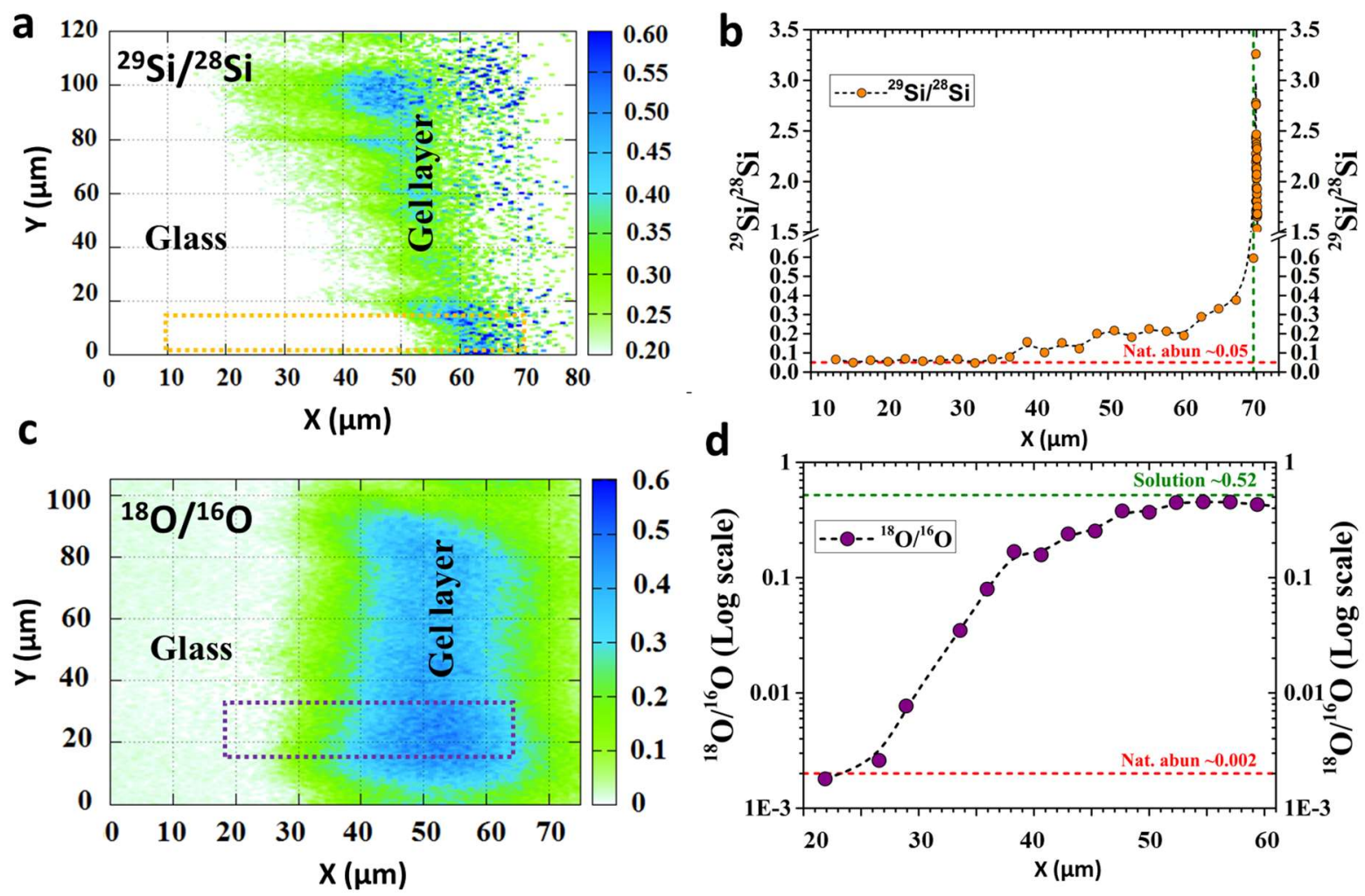

Figure 2. ToF-SIMS characterization of altered CJ1 glass resulting from the short-term stage II rate experiment. a) ${ }^{29} \mathrm{Si} /{ }^{28} \mathrm{Si}$ distribution map; b) ${ }^{29} \mathrm{Si} /{ }^{28} \mathrm{Si}$ profile combining data from the map by averaging values within the delimited area (results displayed on the left side of the green dashed line) and data obtained by depth profiling (on the right side of the green dashed line). This combination was made because it was not possible to analyze the whole layer by depth profiling. c) ${ }^{18} \mathrm{O} /{ }^{16} \mathrm{O}$ distribution map. d) ${ }^{18} \mathrm{O} /{ }^{16} \mathrm{O}$ profile obtained from the map by averaging values within the selected area. The selected areas for calculating profiles are displayed in dashed line on the two maps. 
a

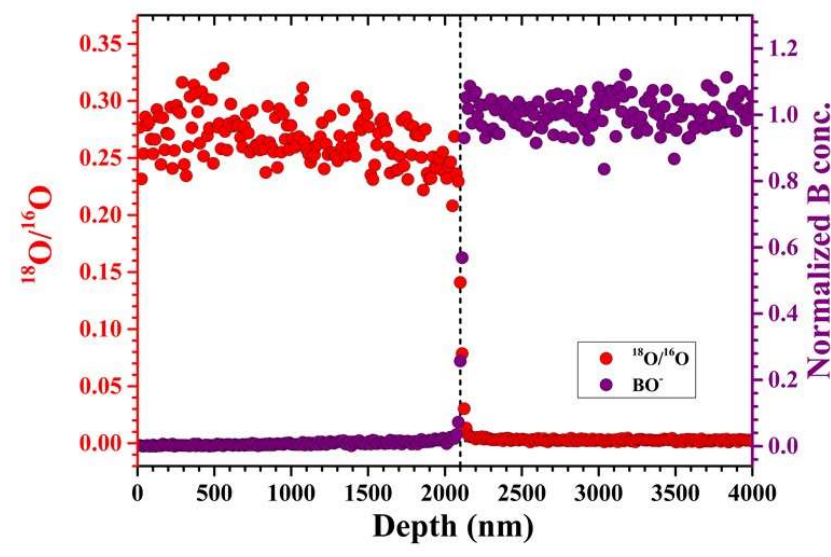

b
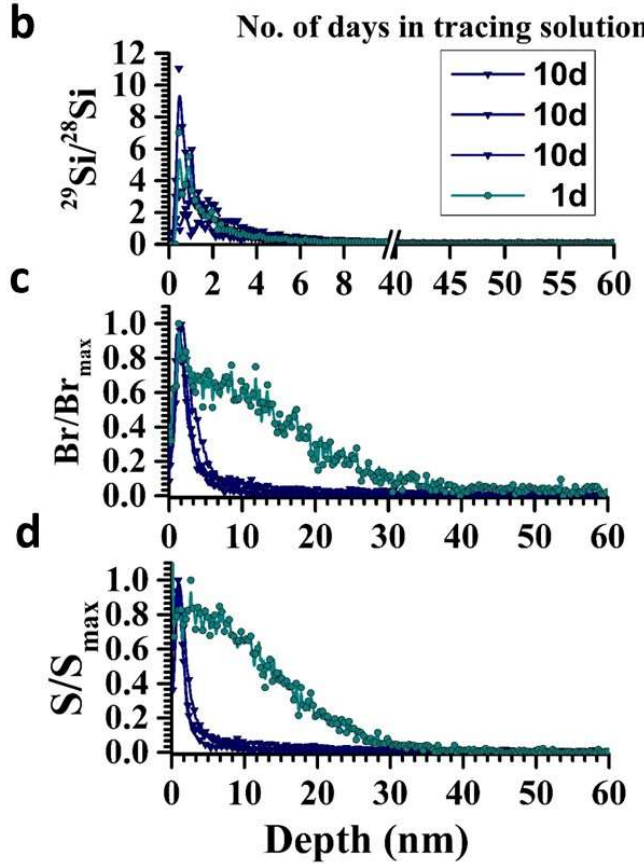

Figure 3. ToF-SIMS characterization of altered CJ2 glass resulting from the short-term stage II rate experiment. a) ${ }^{18} \mathrm{O} /{ }^{16} \mathrm{O}$ and normalized B- profiles. The gel/glass interface is located $2.1 \mu \mathrm{m}$ below the outer surface. This thickness agrees with solution data. b) ${ }^{29} \mathrm{Si} /{ }^{28} \mathrm{Si}$ profile showing an enrichment in isotope 29 only in the first $2 \mathrm{~nm}$ of the gel layer. c) and d) $\mathrm{S}$ and $\mathrm{Br}$ normalized profiles after 1 day and 10 days contacting times in the dye-containing tracing solutions. $\mathrm{Br}$ is the proxy for bromothymol blue only and $\mathrm{S}$ for the two dyes.

\subsection{Morphology of mature gels}

It is shown above that the mechanisms involved in the formation of gels depend on the presence of Al. Other studies also demonstrated that despite saturation of the solution, Ostwald ripening contributes to gels maturation ${ }^{19,45}$. To better understand the evolution of glass in stage II, insights into gel morphology are given by TEM characterization of the CJ1 and CJ2 samples resulting from the long-term stage II experiment (21.4 year-long leaching tests).

CJ1 fully corroded powder is made of altered glass (AG) particles and precipitated silica sols (Figure 4). Figure 4a shows a low magnification image indicating the presence of the altered glass (AG) particles and silica sols. A cluster of the silica sols attached to an AG particle is shown in Figure 4b. A higher magnification image to better visualize the spherical silica sols is shown in Figure 4c. The diameter of the sols ranged from about 90 to $180 \mathrm{~nm}$. They are similar to those observed by Jegou and co-workers at the very first stage of silica precipitation on $\mathrm{CJ} 1^{26}$. Therefore, one might consider them as the stable phases under the tested conditions. Different images showing varying degrees of overlap of the sols and the resulting microstructure are shown in Supplementary Figure S4. A magnified image of the region indicated by the rectangle in Figure $4 \mathrm{c}$ is shown in Figure $4 \mathrm{~d}$ which, as 
indicated by the presence of small bright pores, highlights the porous nature of these AG particles. Detailed microstructure of the porous AG particles is shown in the TEM images of the thin FIB lamella in Figure 4 e-g. Figure 4e (from top to bottom) shows the layers of $\mathrm{C}$ and $\mathrm{Cr}$ deposited for the sample preparation. Underneath the $\mathrm{Cr}$ layer, there is a dense layer labelled as WfL (Water-facing-Layer), which, in principle, would be facing the bulk solution during the process of corrosion. A magnified image showing the WfL is presented in Figure $4 f$. Some silica sols precipitated on top of the WfL and trapped under the $\mathrm{Cr}$ layer are indicated by the arrow in Figure $4 \mathrm{e}$ and a magnified image of the sols is shown in Figure 4g. It is worth noting that the thickness of the WfL and the diameter of the silica sols are similar. Furthermore, on images $4 \mathrm{e}$ and $4 \mathrm{~g}$ one can note that the two materials display the same contrast and do not show any pores. Both are pure silica. It is thus possible to hypothesize that the WfL was made by coalescence of silica sols.

Underneath the WfL, there is a highly porous material with the shape of small glass particles. All the observed altered glass particles are smaller than the original glass grains. This implies that, if these particles are inherited from the original glass grains, a significant part of them have dissolved during the corrosion process. Typical pores in this AG are indicated by the arrow (Figure 4e). Due to the nonspherical shape and overlap of the pores, individual pore size estimates are unreliable, but the typical dimensions of some of the well-isolated pores ranged from up to $30 \mathrm{~nm}$ in diameter and about $80 \mathrm{~nm}$ in length. Also, about $30 \%$ of the projected area was covered by the pores (shown in Supplementary Figure S5). The microstructure of the corroded CJ1 therefore follows the following sequence: [altered glass]-[water facing non porous layer]-[silica sols]. Interestingly, it was observed that all the AG particles were entirely coated with the WfL of pure dense silica. It is therefore likely that the WfL limited the mass transfer between the glass and the solution. In that sense, the $\mathrm{WfL}$ can be considered as a passivation layer formed on the CJ1 glass particle. In this view, the rate-limiting mechanisms changed once partly corroded particles were coated with the WfL. First glass particles dissolved, then sols precipitated, and for the glass particles that were entirely coated by dense amorphous silica, dissolution dramatically slowed down. The remaining corrosion process led to a slow release of $\mathrm{B}$ and $\mathrm{Na}$ followed by maturation of the porous and hydrated silica. It was shown by Gouze et al. that nanopores within mesoporous silica evolve with time despite the saturation of the bulk solution ${ }^{46}$. 


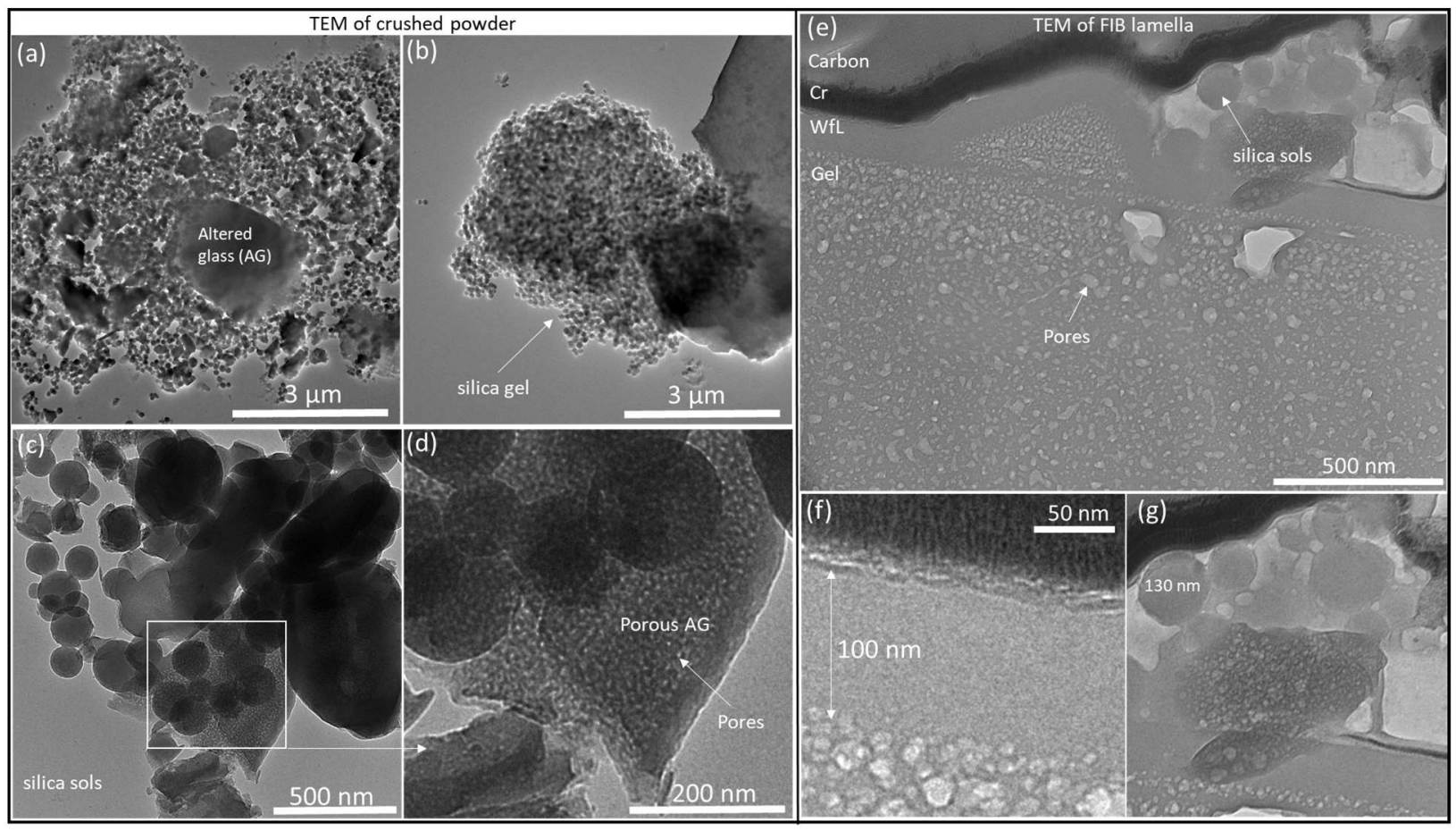

Figure 4. Bright field (BF) TEM of corroded CJ1 powder resulting from the long-term stage II experiment. (a) a low magnification BF-TEM image of the corroded powder showing an altered glass (AG) particle surrounded by silica sols, (b) a cluster of silica sols/silica gel attached to an AG particle, (c) a high magnification image showing the individual silica sols, (d) a magnified image of the region indicated by the rectangle in (c) highlighting the presence of pores in the AG, (e) BF-TEM image of a thin FIB lamella showing the protective carbon and chromium layers, the water facing layer (WfL), and the gel. The pores in the gel and precipitated silica sols on top of the WfL are indicated by the arrows, (f) a higher magnification image showing the microstructure of the $\mathrm{WfL}$ and, $(\boldsymbol{g})$ a magnified image of the trapped silica sols.

SEM and TEM images of the partially corroded CJ2 powder are shown in Figure 5a-k. Figure 5a shows a SEM image of a corroded particle indicating the presence of an altered layer. A higher magnification image of the region indicated by the rectangle is shown in Figure 5a-I showing a thin altered layer ( $p 1$ ), a thicker altered layer (p2) and a smooth region (s). Figure $5 b$ shows a different particle with a p1-like altered layer and the protective carbon deposited to extract the FIB lamella from this region. The microstructure of this FIB lamella is shown in Figure $5 f$ and discussed later.

Figure $5 c-d$ show low and high magnification TEM images of the corroded and crushed CJ2 powder dispersed onto a holey carbon TEM grid. Unlike in the case of CJ1, no silica sols can be seen in these TEM images. To confirm the lack of silica sols, an extensive search was performed but, no sols were observed anywhere on the TEM grid. The absence of sols confirms the hypothesis that CJ2 is less soluble than amorphous silica. However, several thin altered glass flakes, which contained pores, were observed. To better understand the microstructure of the altered CJ2, TEM images of the thin FIB lamellae are shown in Figure 5e-h. Figure 5e shows a low magnification image of (from left to right) the vacuum, protective carbon, protective $\mathrm{Cr}$ and, the altered glass. A higher magnification image to better visualize the microstructure of the altered glass is shown in Figure $5 f$. It shows the 
presence of an outer porous region of about $66 \mathrm{~nm}$ (indicated by the vertical lines) and an inner nanoporous layer. TEM images of a different FIB lamella presented in Figure $5 \mathrm{~g}$ show a much wider and rougher outer porous region of about $420 \mathrm{~nm}$ followed by an inner nanoporous material. The size of the pores present in the heart of the gel followed a log normal distribution (shown by the red line) with a mean pore size and width of $0.7 \pm 0.2 \mathrm{~nm}$ and $0.4 \mathrm{~nm}$, respectively (Figure $5 \mathrm{~h}$ ).

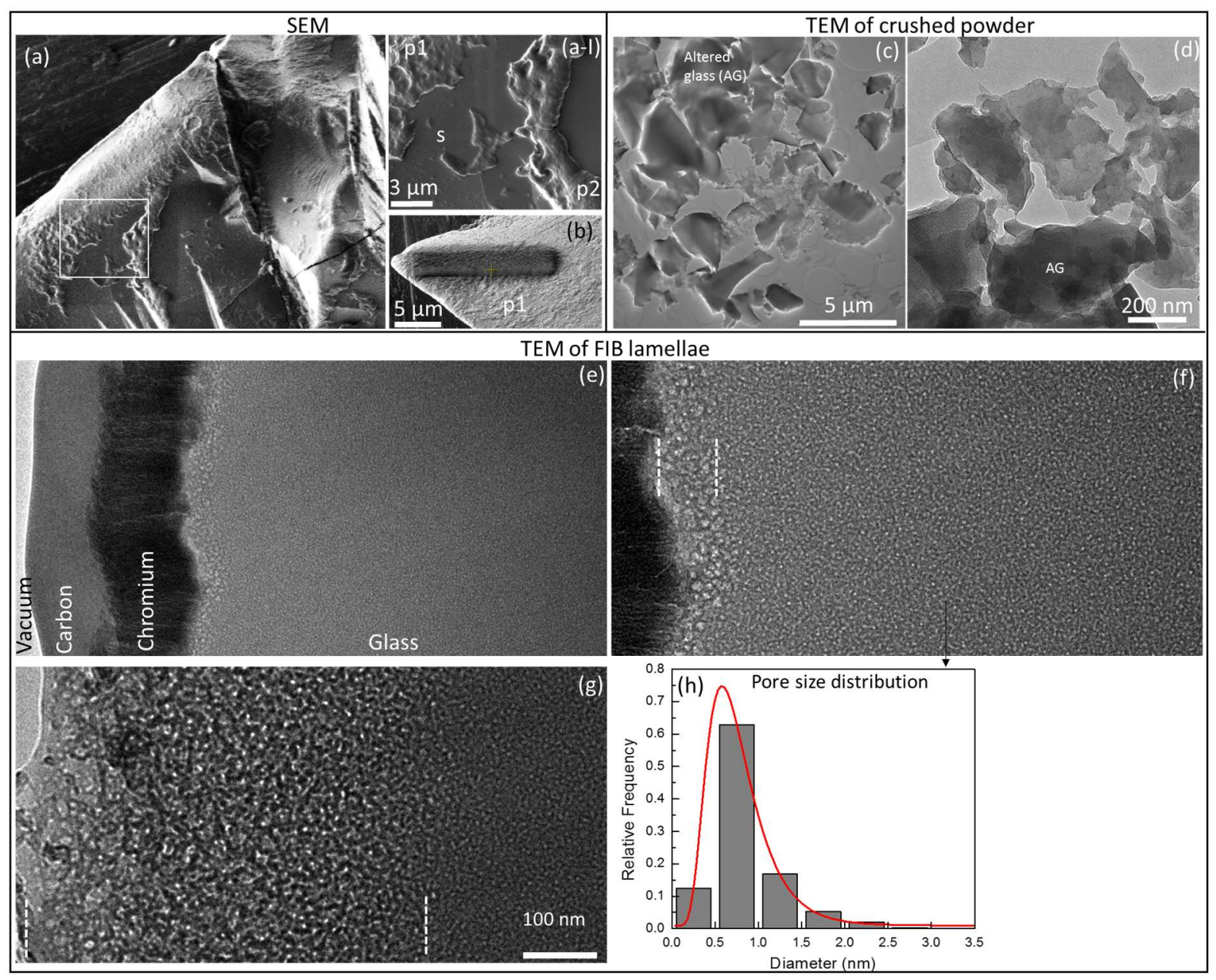

Figure 5. SEM and TEM images of corroded CJ2 resulting from the long-term stage II experiment. (a) A low magnification SEM image of a corroded particle, (a-I) a magnified image of the region indicated by the rectangle to highlight the presence of the precipitated layer. Regions labeled "p1", "p2" highlight fairly rough thin and thick precipitated layers, respectively. Region labeled "s" shows a smooth region without any clearly visible precipitated layer, (b) a "p1-like" region protected by carbon deposition to prepare the FIB TEM lamella from this region, (c) a low magnification TEM image of the crushed CJ2 powder confirming the lack of any silica sols, (d) a magnified image of typical altered glass flakes/particles, (e) a low magnification image of a TEM FIB lamella taken in a "p1-like" region showing protective carbon and $\mathrm{Cr}$ and the altered glass, $(f)$ a magnified image of the altered glass shown in (e) showing the presence of large pores in the outer region demarcated by vertical lines ( $\sim 66 \mathrm{~nm}$ ) and small pores in the inside glass, $(\boldsymbol{g})$ TEM images of a different FIB lamella taken in a "p2-like" region showing a wider outer porous region $(\sim 20 \mathrm{~nm})$ followed by the inner porous glass, (h) Distribution of pores in the corroded CJ2 glass in the nano porous region as indicated by the black arrow (obtained from 9544 pores). The red line shows a log-Normal fit. The scale bar in $(\boldsymbol{g})$ applies to the images $(e, f)$.

\subsection{Monte Carlo simulations}


Here, we present MC simulations aimed at determining whether simple mechanistic assumptions can account for the earlier formation of the passivating layer on CJ1 than on CJ2. For that, the corrosion of $\mathrm{CJ} 1$ and $\mathrm{CJ} 2$ was simulated in static conditions with no dissolved silica initially present in the solution. Figure 6 shows the instantaneous changes in the Si concentration as a function of time, $\Delta C_{\mathrm{si}}(t)$, due to Si dissolved $(d)$ and Si redeposited $(r)$, which are defined as:

$\Delta C_{S i}^{d}(t)=\frac{N_{\mathrm{S}}^{d}(t)}{N_{\mathrm{H}_{2} \mathrm{O}}} \times C_{\mathrm{H}_{2} \mathrm{O}} \times M W_{\mathrm{Si}}$

$\Delta C_{S i}^{r}(t)=-\frac{N_{\mathrm{Si}}^{r}(t)}{N_{\mathrm{H}_{2} \mathrm{O}}} \times C_{\mathrm{H}_{2} \mathrm{O}} \times M W_{\mathrm{Si}}$

where $N_{\mathrm{Si}}^{d}(t)$ and $N_{\mathrm{Si}}^{r}(t)$ are the number of Si sites dissolved from the glass and redeposited on the glass, respectively, at time $t, N_{\mathrm{H}_{2} \mathrm{O}}$ is the total number of water sites representing the bulk solution, $C_{\mathrm{H}_{2} \mathrm{O}}$ is the water concentration $\left(55.5 \mathrm{~mol} \mathrm{~L}^{-1}\right)$, and $M W_{\mathrm{si}}$ is Si molar mass $\left(28.086 \mathrm{~g} \cdot \mathrm{mol}^{-1}\right)$.

The two glasses showed the same qualitative behavior whereby Si was initially dissolved (black and red lines) and the amount of redeposited Si (green and orange lines) began to increase when the Si concentration in solution became sufficiently large. After around 5000 steps, the changes in the $\mathrm{Si}$ concentration due to dissolution and redeposition cancelled each other out and this formally marked the achievement of the equilibrium between the altered glass and solution. The dynamics of dissolution/redeposition events lead to the progressive polymerization of the alteration layer ${ }^{35}$. Because this process is more advanced for the top part of the alteration layer, which has been in contact with the solution for longer, a dense blocking Si layer eventually forms atop the alteration layer and prevents percolation of water from the solution to the pristine glass. The initial formation of this blocking layer happened after around 10000 and 20000 steps for CJ1 and CJ2, respectively. This leads to a sharp decrease in the total reactive surface area (only surface sites connected to the main solution can dissolve, see Section 2.5) and consequently in the number of dissolved and redeposited Si sites at each computer step. As the top of the alteration continues to react with the solution, intermittent opening of the blocking layer can occur, thus momentarily exposing more glass to the main solution, which leads to the spikes in $\Delta C_{S i}^{h}(t)$ and $\Delta C_{S i}^{d}(t)$ in Figure 6. Similarly, the opening of large pores can lead to spikes prior to the formation of the blocking layer. The dissolution of clusters of sites isolated from the main glass matrix (see Section 2.5) ${ }^{33-35}$ can also contribute to spikes in $\Delta C_{S i}^{d}(t)$.

The results of the MC simulations qualitatively explain the behavior of the two glasses in the first months of the long-term tests (Figure $1 \mathrm{~b}$ ). It also confirms the suggestion - that a passivating layer developed sooner on CJ1 - put forward in Section 3.1 to explain the fact that the amount of altered $\mathrm{CJ} 1$ and $\mathrm{CJ} 2$ were close during the first half-year despite a large difference in their initial dissolution rates. Note that because diffusion inside the gel and pore ripening are not implemented in the current 
version of the $\mathrm{MC}$ code, it is not possible to discuss the advanced stage of glass reaction, and particularly the values of the residual rate.

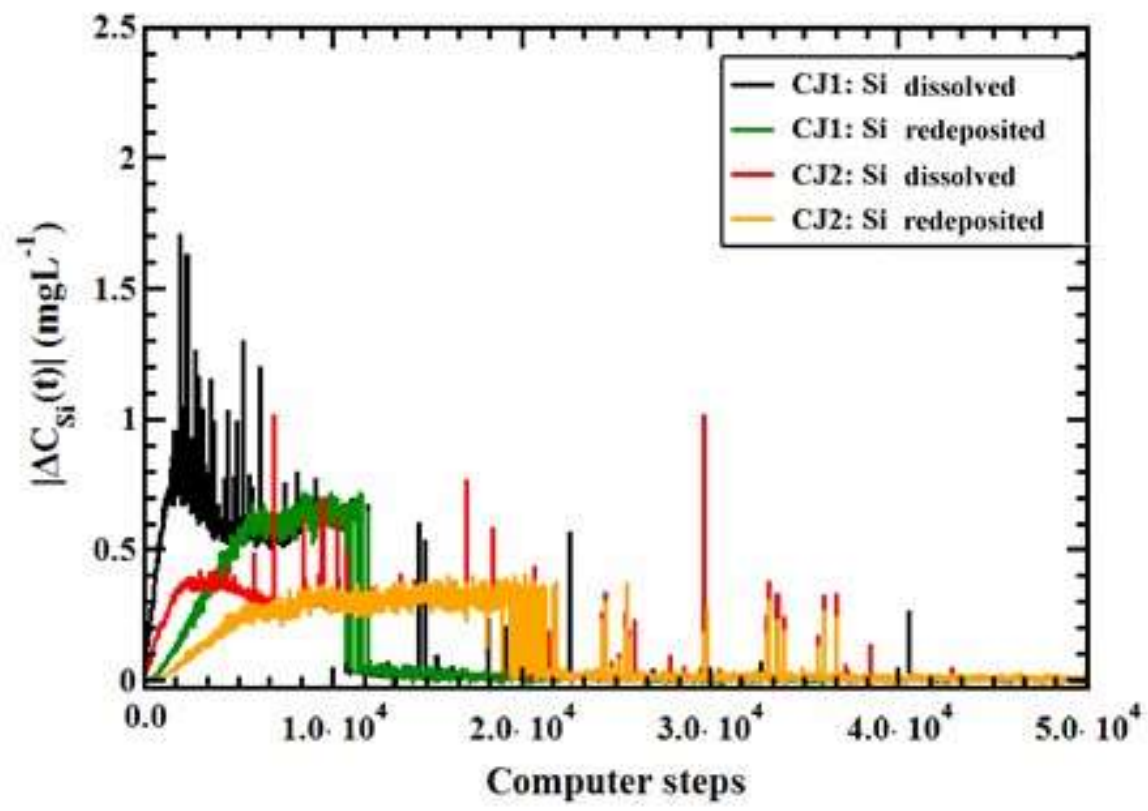

Figure 6. Instantaneous change in the concentration of Si dissolved $\left(\Delta C_{S i}^{d}\right.$ in Equation 7) and Si redeposited $\left(\Delta C_{S i}^{r}\right.$ in Equation 8) during alteration of $\mathrm{CJ} 1$ and $\mathrm{CJ} 2$ versus the number of $\mathrm{MC}$ steps.

To go further, let us discuss the chemical composition and the morphology of the gel and blocking layer formed on the two glasses. The $\mathrm{Si}$ (or Si+Al for $\mathrm{CJ} 2$ ) concentration progressively decreases when going from the outer surface towards the pristine glass (right to left in Figure 7), indicating the outer part of the gel densifies as the reaction progresses in agreement with previous experimental work ${ }^{47}$. Moreover, the fraction of $\mathrm{Si}(\mathrm{Si}+\mathrm{Al}$ for $\mathrm{CJ} 2)$ rapidly dropped to zero at the interface between the gel and the solution, and this drop was steeper for $\mathrm{CJ} 1$ than for $\mathrm{CJ} 2$, indicating that the gel/solution interface is rougher for $\mathrm{CJ} 2$ than for $\mathrm{CJ} 1$.

Figure $7 \mathrm{~b}$ shows the quantity of glass sites exposed to water, either water in the main solution or water in closed pores. Globally, the curves are similar for the two glasses. Inside the gel, the number of water molecules trapped in closed pores increases with depth. Glass sites connected to the main solution are logically concentrated in the outer part of the gel. For $\mathrm{CJ} 2$, the fraction of sites exposed to the main solution is higher and their distribution is broader than for $\mathrm{CJ} 1$, underlying again the rougher gel/solution interface.

Figure 7c shows snapshots of the morphologies of the alteration layers of CJ1 (top) and CJ2 (bottom) after the blocking layers were formed. Only the upper parts of the gels are displayed to highlight the most interesting results. The gel/solution interface of CJ2 is significantly rougher than that of CJ1. Al slows down the dissolution of the CJ2 network by creating "hard spots" that are difficult to dissolve. 
Water circumvents these more durable spots, creating the heterogeneities at the origin of the difference in roughness and tortuosity between the two glasses. This result is also consistent with the surface roughening observed when ISG, a glass containing Al and Zr, initially dissolves ${ }^{48}$.
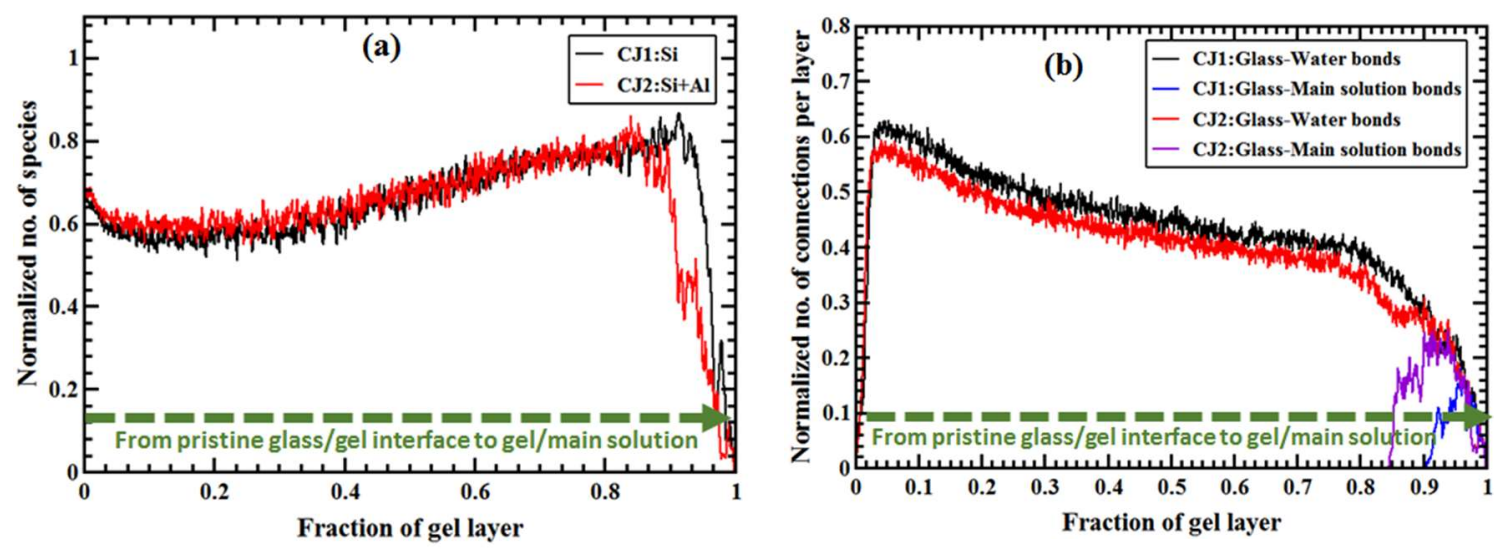

(c) Glass $4 \ldots \ldots$. n... - $\Rightarrow$ Solution
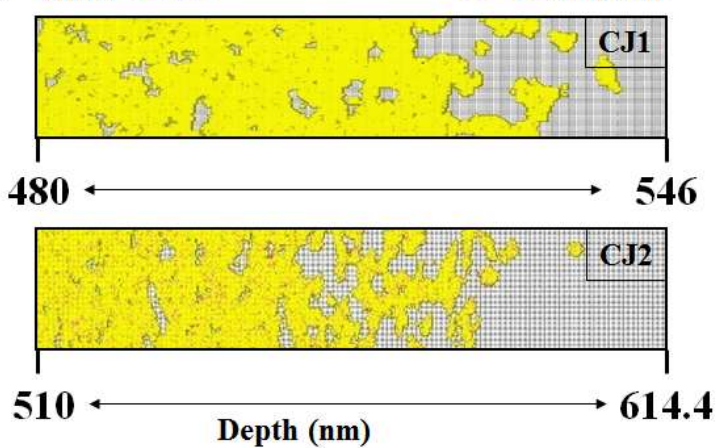

Figure 7. Cross sections of the gel layers after formation of the blocking layer for CJ1 (taken at 17000 steps) and CJ2 (taken at 50000 steps) (a) Fraction of $\mathrm{Si}$ (for CJ1) and $\mathrm{Si}+\mathrm{Al}$ (for CJ2) sites as a function of depth inside the gel layer (normalized by the gel layer thickness; 0 and 1 are thus the locations of the pristine glass/gel and gel/solution interfaces, respectively) (b) Fraction of glass sites exposed to water sites inside closed pores (black and red lines) and water sites in the main solution (purple and blue lines) as a function of depth inside the gel layer. (c) Snapshot of the CJ1 and CJ2 gel layers (Si sites are shown in yellow, Al sites in red, and water sites in grey).

\section{Discussion}

The experiments conducted at short, intermediate, and advanced reaction progress, show that CJ1 and $\mathrm{CJ} 2$ glasses appear to behave differently despite their slight compositional difference. As expected, the Al-bearing glass dissolved much slower than CJ1 far from equilibrium. This is in agreement with previous experimental and modeling studies ${ }^{34,40-41}$ and can be explained if one considers that, in alkaline medium, the energy barrier for hydrolysis of $\mathrm{Si}-\mathrm{O}-\mathrm{Al}$ bonds is higher than for $\mathrm{Si}-\mathrm{O}-\mathrm{Si}$ bonds. Another positive aspect of adding $\mathrm{Al}$ to $\mathrm{Na}$-borosilicate glasses is that it reduces the fraction of glass modifiers, as one Al atom takes one $\mathrm{Na}$ atom as charge compensator. 
Furthermore, once the solution is saturated with respect to silica, both glasses can form a Si-rich passivating layer allowing the rate to eventually decrease by 2 to 3 orders of magnitude compared to $R_{0}$, but the mechanisms responsible for the formation of the passivating layer are different. The data collected from $\mathrm{O}$ and $\mathrm{Si}$ isotopes suggest that $\mathrm{Si}$ tetrahedra of the $\mathrm{CJ} 1$ network undergo complete hydrolysis at the beginning of the reaction, then dissolved species reprecipitate once the bulk solution is super saturated. Precipitation lead to the formation of sol particles on the glass surface only (low $S / V$ ), or both on the glass surface and in the solution (high $S / V$ ). Progressively, the Si-rich layer densifies and contributes to retain hydrolyzed Si at the buried glass surface. The fact that the ${ }^{29} \mathrm{Si} /{ }^{28} \mathrm{Si}$ displays a marked gradient within the core of the gel of $\mathrm{CJ} 1$ (Figure $2 \mathrm{~b}$ ) suggests that the mobility of Si within the gel is low. A high mobility (complete hydrolysis of Si atoms, diffusion of $\mathrm{H}_{4} \mathrm{SiO}_{4}$ in pore water and re-condensation) would have given a more uniform isotopic profile. It is worth noting that the precipitation of sols is favored under alkaline $\mathrm{pH}$ and in the presence of alkalis ${ }^{49}$. Because the long-term stage II experiment was conducted at a much higher $S / V$ than the shortterm stage II experiment, both the flux of Si released by the glass particles at the beginning of the experiment and the Na concentration were higher in the long-term experiment. This can explain why we found a large amount of sols only in the long-term experiment.

Unlike CJ1, most of the gel of $\mathrm{CJ} 2$ did not show an enrichment of ${ }^{29} \mathrm{Si}$, suggesting that this gel was formed only by in-situ reorganization of the silicate network after release of the mobile elements ( $\mathrm{Na}, \mathrm{B})$. In this case, in-situ reorganization means that it was not necessary to break all the bonds linking a Si atom to the glass network to form a new bond between two adjacent Si atoms, initially separated by a B atom or a non-bridging oxygen. The process of reorganization, involving bond breaking and bond forming, is supported by the high enrichment of ${ }^{18} \mathrm{O}$ measured in the gel. However, the $\mathrm{O}$ isotopic ratio of the gel formed on $\mathrm{CJ} 2$ does not reach that of the bulk solution. This indicates that not all the covalent bonds have been broken. Moreover, a previous study conducted with ISG under similar conditions $\left(90^{\circ} \mathrm{C}, \mathrm{pH} 9\right.$, silica saturated solution spiked with $\left.{ }^{29} \mathrm{Si}\right)$ demonstrated that the slight amount of ${ }^{29} \mathrm{Si}$ which entered the gel was not strongly bonded to the gel skeleton ${ }^{44}$. These two observations suggest that most of the Si atoms of the glass were not fully hydrolyzed during corrosion of $\mathrm{CJ} 2$. Furthermore, another study conducted on ISG $\left(90^{\circ} \mathrm{C}, \mathrm{pH} 7\right.$, silica saturated solution spiked with ${ }^{29} \mathrm{Si}$ ) demonstrated that the passivating gel continues to undergo hydrolysis and condensation reactions even after its formation ${ }^{19}$, leading to pore ripening, with higher porosity and bigger pore in the outer layer ${ }^{45}$, a process that could also explain the observations made on the CJ2 sample after 21.4 years of alteration.

On $\mathrm{CJ} 2$, the isotopically tagged experiment showed a $2 \mathrm{~nm}$ thick, ${ }^{29} \mathrm{Si}$ enriched layer formed on the top of the gel. This layer represents only $1 / 1000^{\text {th }}$ of the whole alteration layer and can be explained 
by a complete reorganization and roughening of the extreme surface ${ }^{48}$. This outer layer is not protective as demonstrated by the penetration of dyes below this outermost layer. This makes a difference between the two glasses as it was suggested that the outer precipitated layer formed on CJ1 was responsible for the first step of passivation of the glass surface characterized by the change of the corrosion process (dissolution/reprecipitation $\rightarrow$ in-situ reorganization). This is a new paradigm as it is generally claimed within the glass corrosion community that secondary phases precipitates at the expense of passivating gel ${ }^{1,3}$. Here we show that a precipitate can be passivating or can favor passivation. This has been already reported for minerals such as olivine ${ }^{50}$. Interestingly, a recent study showed that a glass more soluble than $\mathrm{CJ} 1\left(60.2 \mathrm{SiO}_{2}, 20 \mathrm{~B}_{2} \mathrm{O}_{3}, 19.8 \mathrm{Na}_{2} \mathrm{O}\right.$ in mol\%) undergoes congruent interfacial dissolution followed by reprecipitation of a non-passivation amorphous silica layer, leading to a pH gradient between the reacting interface and the bulk solution ${ }^{51}$. Unfortunately, the experiments were conducted for only a few days and it is not known if the precipitated layer eventually densifies and change the corrosion process. Nonetheless this study indicates that for highly soluble glasses local pH at the reacting interface can differ from the bulk.

To date the roughening of the outer surface has not been considered as an important phenomenon for glass corrosion. However, our MC simulations show that the presence of Al creates a rougher interface than for CJ1 due to the preferential dissolution of Al-poor clusters. Although the behavior of dyes showed that these nano-cavities are connected to the bulk solution, one can assume that the resulting constricted geometry favored the local super-saturation of the fluid and redeposition of dissolved silica whilst the bulk solution is not saturated. This idea is supported by previous MC simulations including diffusion of dissolved species through the gel layer ${ }^{52}$.

As a whole, our results strongly suggest that for both glasses the outer layer plays an important role. It equilibrates with the bulk solution and creates local conditions allowing the glass to develop a passivating layer by in-situ hydrolysis and condensation reactions within the silicate network, leading to pore closure slowing down diffusion of aqueous species. Here we demonstrate that this phenomenon can occur for sparingly soluble glasses after surface roughening and highly soluble borosilicate glasses after precipitation of a continuous dense layer of amorphous silica on the reacting glass surface.

Figure 8 summarizes the main findings of this study in a unified alteration process scheme involving a series of hydrolysis and condensation reactions leading to partial or complete cation detachment (here $\mathrm{Si}$ and $\mathrm{Al}$ ) at the glass(or-gel)/water interface depending on glass composition and solution chemistry. These reactions, along with the dissolution of soluble species (B, Na), yield a porous structure (gel) with varying extent of reorganization that can impede the transport of water and eventually slow down further alteration. 

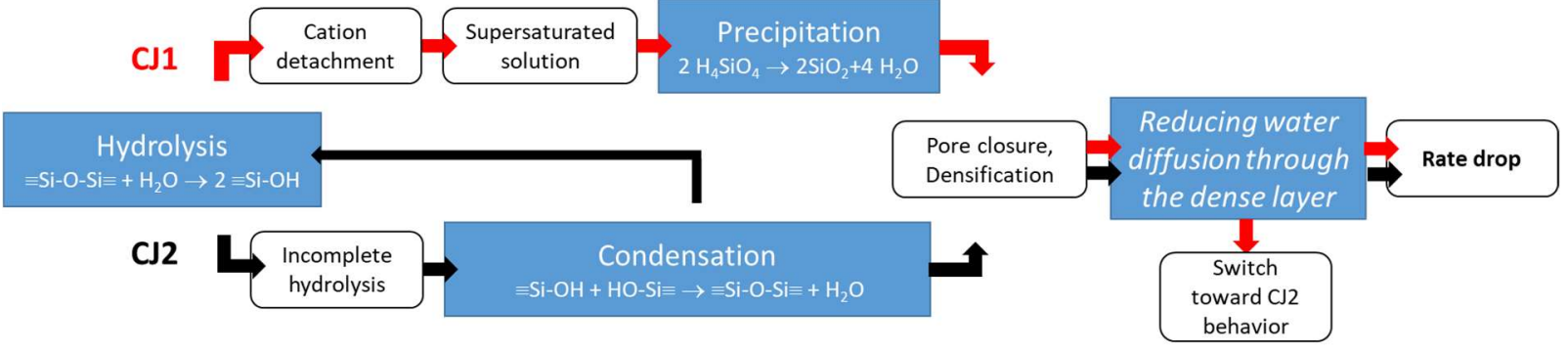

Figure 8. Diagram showing how CJ1 and CJ2 dissolve. Blue boxes refer to a given mechanism, while white boxes refer to a consequence of a given mechanism on glass behavior. Italic text is used for a mechanism hypothesized from previous work but not demonstrated here.

\section{Conclusion}

Here we demonstrate that there is no reason to oppose the different models recalled in the introduction (dissolution/precipitation and partial hydrolysis followed by in situ reorganization of the silicate network) and vigorously debated in the literature ${ }^{16-17,20}$. During the course of a single experiment CJ1 glass experienced a stage controlled by dissolution/precipitation followed by one governed by in-situ reorganization of the silicate network. In the alkaline conditions studied in this work, the presence of a hardening element such as Al favored the second mechanisms. Using an experimental approach and Monte Carlo simulations, it was shown that Al dramatically affected the initial stage of glass dissolution as well as the gel features (chemical composition, porosity and roughness). It explains why a protective layer formed more rapidly on the CJ1 glass compared to CJ2 because of the faster release of the elements in solution. Finally, an explanation is proposed to the switching of the alteration mechanisms between $\mathrm{CJ} 1$ and $\mathrm{CJ} 2$ based on an increase of the glass solution roughness with possible consequences on the diffusion of the dissolved species.

\section{Acknowledgements}

The authors are grateful to Géraldine Parisot, Fréderic Angeli and Thibault Charpentier (CEA), for technical support and scientific input. The planning and strategy of this work, the Monte Carlo simulations, the execution of the short-term experiments, solution and ToF-SIMS analyses were supported as part of the Center for Performance and Design of Nuclear Waste Forms and Containers, an Energy Frontier Research Center funded by the U.S. Department of Energy (DOE), Office of Science, Basic Energy Sciences under Award \#DESC0016584. 
The TEM work undertaken at the University of Huddersfield was supported by the Engineering and Physical Research Council (EPSRC) grants EP/E017266/1, EP/M011135/1 and EP/M028283/1 of the United Kingdom.

\section{Supporting Information}

Structural information on both glasses, leaching data, and gel characteristics observed by SEM and TEM.

\section{References}

1. Gin, S., et al., An International Initiative on Long-Term Behavior of High-Level Nuclear Waste Glass. Materials Today 2013, 16, 243-248.

2. Grambow, B., Nuclear Waste Glasses - How Durable? Elements 2006, 2, 357-364.

3. Vienna, J. D.; Ryan, J. V.; Gin, S.; Inagaki, Y., Current Understanding and Remaining Challenges in Modeling Long-Term Degradation of Borosilicate Nuclear Waste Glasses. International Journal of Applied Glass Science 2013, 4, 283-294.

4. Guo, X., et al., Self-Accelerated Corrosion of Nuclear Waste Forms at Material Interfaces. Nature Materials 2020.

5. Frugier, P.; Minet, Y.; Rajmohan, N.; Godon, N.; Gin, S., Modeling Glass Corrosion with Graal. npj Materials Degradation 2018, 2, 35.

6. Grambow, B.; Muller, R., First-Order Dissolution Rate Law and the Role of Surface Layers in Glass Performance Assessment. Journal of Nuclear Materials 2001, 298, 112-124.

7. Pierce, E. M.; Frugier, P.; Criscenti, L. J.; Kwon, K. D.; Kerisit, S. N., Modeling Interfacial GlassWater Reactions: Recent Advances and Current Limitations. International Journal of Applied Glass Science 2014, 5, 421-435.

8. Gin, S., Open Scientific Questions About Nuclear Glass Corrosion. In 2nd International Summer School on Nuclear Glass Wasteform: Structure, Properties and Long-Term Behavior, Angeli, F.; Delaye, J. M.; Schuller, S.; Pinet, O.; Rebiscoul, D.; Gin, S.; Peuget, S., Eds. Elsevier Science Bv: Amsterdam, 2014; Vol. 7, pp 163-171.

9. Bunker, B. C., Molecular Mechanisms for Corrosion of Silica and Silicate-Glasses. Journal of Non-Crystalline Solids 1994, 179, 300-308.

10. Frugier, P., et al., Son68 Nuclear Glass Dissolution Kinetics: Current State of Knowledge and Basis of the New Graal Model. Journal of Nuclear Materials 2008, 380, 8-21.

11. Gin, S., Protective Effect of the Alteration Gel: A Key Mechanism in the Long-Term Behavior of Nuclear Waste Glass. In Scientific Basis for Nuclear Waste Management Xxiv, Hart, K. P.; Lumpkin, G. R., Eds. Materials Research Society: Warrendale, 2000; Vol. 663, pp 207-215.

12. Frankel, G. S.; Vienna, J. D.; Lian, J.; Scully, J. R.; Gin, S.; Ryan, J. V.; Wang, J.; Kim, S. H.; Windl, W.; Du, J., A Comparative Review of the Aqueous Corrosion of Glasses, Crystalline Ceramics, and Metals. npj Materials Degradation 2018, 2, 15.

13. Frugier, P.; Martin, C.; Ribet, I.; Advocat, T.; Gin, S., The Effect of Composition on the Leaching of Three Nuclear Waste Glasses: R7t7, Avm and Vrz. Journal of Nuclear Materials 2005, 346, 194-207. 14. Gin, S.; Frugier, P.; Jollivet, P.; Bruguier, F.; Curti, E., New Insight into the Residual Rate of Borosilicate Glasses: Effect of S/V and Glass Composition. International Journal of Applied Glass Science 2013, 4, 371-382.

15. Vernaz, E.; Gin, S.; Jegou, C.; Ribet, I., Present Understanding of R7t7 Glass Alteration Kinetics and Their Impact on Long-Term Behavior Modeling. Journal of Nuclear Materials 2001, 298, 27-36. 
16. Hellmann, R.; Cotte, S.; Cadel, E.; Malladi, S.; Karlsson, L. S.; Lozano-Perez, S.; Cabie, M.; Seyeux, A., Nanometre-Scale Evidence for Interfacial Dissolution-Reprecipitation Control of Silicate Glass Corrosion. Nature Materials 2015, 14, 307-311.

17. Geisler, T.; Nagel, T.; Kilburn, M. R.; Janssen, A.; Icenhower, J. P.; Fonseca, R. O. C.; Grange, M.; Nemchin, A. A., The Mechanism of Borosilicate Glass Corrosion Revisited. Geochimica Et Cosmochimica Acta 2015, 158, 112-129.

18. McGrail, B. P., et al., The Structure of Na2o-Al2o3-Sio2 Glass: Impact on Sodium Ion Exchange in $\mathrm{H} 2 \mathrm{O}$ and D2o. Journal of Non-Crystalline Solids 2001, 296, 10-26.

19. Gin, S.; Collin, M.; Jollivet, P.; Fournier, M.; Minet, Y.; Dupuy, L.; Mahadevan, T.; Kerisit, S.; Du, J. C., Dynamics of Self-Reorganization Explains Passivation of Silicate Glasses. Nature Communications 2018, 9.

20. Gin, S.; Jollivet, P.; Fournier, M.; Angeli, F.; Frugier, P.; Charpentier, T., Origin and Consequences of Silicate Glass Passivation by Surface Layers. Nature Communications 2015, 6.

21. Cailleteau, C.; Angeli, F.; Devreux, F.; Gin, S.; Jestin, J.; Jollivet, P.; Spalla, O., Insight into Silicate-Glass Corrosion Mechanisms. Nature Materials 2008, 7, 978-983.

22. Cailleteau, C.; Devreux, F.; Spalla, O.; Angeli, F.; Gin, S., Why Do Certain Glasses with a High Dissolution Rate Undergo a Low Degree of Corrosion? Journal of Physical Chemistry C 2011, 115, 5846-5855.

23. Ledieu, A.; Devreux, F.; Barboux, P., Monte Carlo Simulations of Borosilicate Glass Corrosion: Predictions for Morphology and Kinetics. Journal of Non-Crystalline Solids 2004, 345, 715-719.

24. Gin, S.; Beaudoux, X.; Angeli, F.; Jegou, C.; Godon, N., Effect of Composition on the ShortTerm and Long-Term Dissolution Rates of Ten Borosilicate Glasses of Increasing Complexity from 3 to 30 Oxides. Journal of Non-Crystalline Solids 2012, 358, 2559-2570.

25. Fournier, M.; Ducasse, T.; Perez, A.; Barchouchi, A.; Daval, D.; Gin, S., Effect of Ph on the Stability of Passivating Gel Layers Formed on International Simple Glass. Journal of Nuclear Materials 2019, 524, 21-38.

26. Jegou, C.; Gin, S.; Larche, F., Alteration Kinetics of a Simplified Nuclear Glass in an Aqueous Medium: Effects of Solution Chemistry and of Protective Gel Properties on Diminishing the Alteration Rate. Journal of Nuclear Materials 2000, 280, 216-229.

27. Fournier, M.; Ull, A.; Nicoleau, E.; Inagaki, Y.; Odorico, M.; Frugier, P.; Gin, S., Glass Dissolution Rate Measurement and Calculation Revisited. Journal of Nuclear Materials 2016, 476, 140-154.

28. Icenhower, J. P.; Steefel, C. I., Experimentally Determined Dissolution Kinetics of Son68 Glass at 90 Degrees $C$ over a Silica Saturation Interval: Evidence against a Linear Rate Law. Journal of Nuclear Materials 2013, 439, 137-147.

29. Gourgiotis, A.; Ducasse, T.; Barker, E.; Jollivet, P.; Gin, S.; Bassot, S.; Cazala, C., Silicon Isotope Ratio Measurements by Inductively Coupled Plasma Tandem Mass Spectrometry for Alteration Studies of Nuclear Waste Glasses. Analytica Chimica Acta 2017, 954, 68-76.

30. Angeli, F.; Charpentier, T.; de Ligny, D.; Cailleteauz, C., Boron Speciation in Soda-Lime Borosilicate Glasses Containing Zirconium. Journal of the American Ceramic Society 2010, 93, 26932704.

31. Collin, M.; Gin, S.; Jollivet, P.; Dupuy, L.; Dauvois, V.; Duffours, L., Tof-Sims Depth Profiling of Altered Glass. npj Materials Degradation 2019, 3, 14.

32. Schindelin, J., et al., Fiji: An Open-Source Platform for Biological-Image Analysis. Nature Methods 2012, 9, 676-682.

33. Kerisit, S.; Pierce, E. M., Monte Carlo Simulations of the Dissolution of Borosilicate and Aluminoborosilicate Glasses in Dilute Aqueous Solutions. Geochimica Et Cosmochimica Acta 2011, 75, 5296-5309.

34. Kerisit, S.; Ryan, J. V.; Pierce, E. M., Monte Carlo Simulations of the Corrosion of Aluminoborosilicate Glasses. Journal of Non-Crystalline Solids 2013, 378, 273-281.

35. Kerisit, S.; Pierce, E. M., Monte Carlo Simulations of the Dissolution of Borosilicate Glasses in near-Equilibrium Conditions. Journal of Non-Crystalline Solids 2012, 358, 1324-1332. 
36. Devreux, F.; Barboux, P.; Filoche, M.; Sapoval, B., A Simplified Model for Glass Dissolution in Water. Journal of Materials Science 2001, 36, 1331-1341.

37. Ledieu, A.; Devreux, F.; Barboux, P.; Minet, Y., Contribution of Monte Carlo Modeling to Understanding the Alteration of Nuclear Glasses by Water. Nuclear Science and Engineering 2006, 153, 285-300.

38. Devreux, F.; Ledieu, A.; Barboux, P.; Minet, Y., Leaching of Borosilicate Glasses. Ii. Model and Monte-Carlo Simulations. Journal of Non-Crystalline Solids 2004, 343, 13-25.

39. Ledieu, A.; Devreux, F.; Barboux, P.; Sicard, L.; Spalla, O., Leaching of Borosilicate Glasses. I. Experiments. Journal of Non-Crystalline Solids 2004, 343, 3-12.

40. Ledieu, A.; Devreux, F.; Barboux, P., The Role of Aluminium in the Durability of AluminoBorosilicate Glasses. Physics and Chemistry of Glasses 2005, 46, 12-20.

41. Hamilton, J. P.; Brantley, S. L.; Pantano, C. G.; Criscenti, L. J.; Kubicki, J. D., Dissolution of Nepheline, Jadeite and Albite Glasses: Toward Better Models for Aluminosilicate Dissolution. Geochimica Et Cosmochimica Acta 2001, 65, 3683-3702.

42. Linard, Y.; Advocat, T.; Jegou, C.; Richet, P., Thermochemistry of Nuclear Waste Glasses: Application to Weathering Studies. Journal of Non-Crystalline Solids 2001, 289, 135-143.

43. Gin, S.; Jollivet, P.; Fournier, M.; Berthon, C.; Wang, Z. Y.; Mitroshkov, A.; Zhu, Z. H.; Ryan, J. V., The Fate of Silicon During Glass Corrosion under Alkaline Conditions: A Mechanistic and Kinetic Study with the International Simple Glass. Geochimica Et Cosmochimica Acta 2015, 151, 68-85.

44. Gin, S.; Jollivet, P.; Rossa, G. B.; Tribet, M.; Mougnaud, S.; Collin, M.; Fournier, M.; Cadel, E.; Cabie, M.; Dupuy, L., Atom-Probe Tomography, Tem and Tof-Sims Study of Borosilicate Glass Alteration Rim: A Multiscale Approach to Investigating Rate-Limiting Mechanisms. Geochimica Et Cosmochimica Acta 2017, 202, 57-76.

45. Ngo, D.; Liu, H.; Sheth, N.; Lopez-Hallman, R.; Podraza, N. J.; Collin, M.; Gin, S.; Kim, S. H., Spectroscopic Ellipsometry Study of Thickness and Porosity of the Alteration Layer Formed on International Simple Glass Surface in Aqueous Corrosion Conditions. npj Materials Degradation 2018, $2,20$.

46. Gouze, B.; Cambedouzou, J.; Parres-Maynadie, S.; Rebiscoul, D., How Hexagonal Mesoporous Silica Evolves in Water on Short and Long Term: Role of Pore Size and Silica Wall Porosity. Microporous and Mesoporous Materials 2014, 183, 168-176.

47. Rebiscoul, D.; Van der Lee, A.; Rieutord, F.; Ne, F.; Spalla, O.; El-Mansouri, A.; Frugier, P.; Ayral, A.; Gin, S., Morphological Evolution of Alteration Layers Formed During Nuclear Glass Alteration: New Evidence of a Gel as a Diffusive Barrier. Journal of Nuclear Materials 2004, 326, 9-18. 48. Ngo, D.; Liu, H.; Kaya, H.; Chen, Z.; Kim, S. H., Dissolution of Silica Component of Glass Network at Early Stage of Corrosion in Initially Silica-Saturated Solution. Journal of the American Ceramic Society 2019, 102, 6649-6657.

49. Iler, R. K., The Chemistry of Silica; John Wiley \& Sons, 1979, p 835.

50. Saldi, G. D.; Daval, D.; Guo, H.; Guyot, F.; Bernard, S.; Le Guillou, C.; Davis, J. A.; Knauss, K. G., Mineralogical Evolution of Fe-Si-Rich Layers at the Olivine-Water Interface During Carbonation Reactions. American Mineralogist 2015, 100, 2655-2669.

51. Geisler, T.; Dohmen, L.; Lenting, C.; Fritzsche, M. B. K., Real-Time in Situ Observations of Reaction and Transport Phenomena During Silicate Glass Corrosion by Fluid-Cell Raman Spectroscopy. Nature Materials 2019, 18, 342-348.

52. Kerisit, S.; Pierce, E. M.; Ryan, J. V., Monte Carlo Simulations of Coupled Diffusion and Surface Reactions During the Aqueous Corrosion of Borosilicate Glasses. Journal of Non-Crystalline Solids 2015, 408, 142-149. 